\title{
Creep Strain Analysis and an Improved Creep Model of Granite Based on the Ratio of Deviatoric Stress- Peak Strength under Different Confining Pressures
}

\section{Li Qian ( $\sim$ qianl64@yahoo.com )}

Sichuan University

Jianhai Zhang

Sichuan University

Xianliang Wang

Sichuan University

Yonghong $\mathrm{Li}$

Power China Chengdu Engineering Corporation Limited

Ru Zhang

Sichuan University

Nuwen Xu

Sichuan University

Zhiguo Li

power china chengdu engineering corporation Limited

\section{Research Article}

Keywords: Deviatoric stress to peak strength ratio, Instantaneous strain, Creep strain analysis, Improved generalized Kelvin model

Posted Date: March 18th, 2021

DOI: https://doi.org/10.21203/rs.3.rs-317168/v1

License: (c) (1) This work is licensed under a Creative Commons Attribution 4.0 International License.

Read Full License

Version of Record: A version of this preprint was published at Environmental Earth Sciences on February 1st, 2022. See the published version at https://doi.org/10.1007/s12665-022-10241-y. 


\title{
Creep Strain Analysis and an Improved Creep Model of Granite Based on the Ratio of Deviatoric Stress-Peak Strength under Different Confining Pressures
}

\author{
Li Qian", ", Jianhai Zhang1, Xianliang Wang', Yonghong Li², Ru Zhang ${ }^{1}$, Nuwen Xu' ${ }^{1}$ Zhiguo Li \\ ${ }^{1}$ State Key Laboratory of Hydraulics and Mountain River Engineering, College of Water Resources and \\ Hydropower, Sichuan University, Chengdu 610065, China, *E.mail: qianl64@yahoo.com \\ ${ }^{2}$ Power China Chengdu Engineering Corporation Limited, Chengdu 610072, China
}

\begin{abstract}
Creep refers to the deformation of rock with time under long-term applied stress, which occur in most underground engineering. The creep behavior of granite in Shuang jiangkou underground powerhouse in Western Sichuan Province, China, was studied by creep tests. Based on test results, a new parameter $D P R$, the ratio of deviatoric stress to peak strength, is proposed. $D P R$ is found to be a key parameter to describe creep parameters such as instantaneous elastic modulus, creep elastic modulus, and viscosity coefficient of rock under different confining pressures. Creep tests show that instantaneous elastic modulus increases with the increase of $D P R$. Creep elastic modulus increases when $D P R$ changes from 0.54 to 0.7004 , but decreases when $D P R$ is from 0.7004 to 0.88 , indicating fractures in rock closes firstly and then new fractures are generated. The viscosity coefficient of the rock increases first and then decreases with the increase of $D P R$, and when $D P R=0.7171$, viscosity coefficient is maximum, indicating the time for rock to reach stability is the longest in creep tests. By introducing $D P R$ and confining pressure into creep model, which interconnect creep parameters in a unified expression, an improved generalized Kelvin creep model is proposed which can accurately describe the primary and the secondary creep behavior of granite under given deviatoric stresses and confining pressures.
\end{abstract}

Keywords: Deviatoric stress to peak strength ratio; Instantaneous strain; Creep strain analysis; Improved generalized Kelvin model

\section{INTRODUCTION}

The time-dependent (creep) behavior of rock refers to the continuous deformation under constant applied stress ${ }^{[1,2]}$. The deformation does not occur instantaneously, but is a time-dependent delayed deformation ${ }^{[3,4]}$. The creep behavior is obvious in soft rocks ${ }^{[5]}$, but hard rocks under high stress can also exhibit obvious creep behavior. Excessive deformation caused by creep can affect the design function of rock infrastructure and increase the repair $\operatorname{cost}^{[6]}$. Therefore, creep characteristics is a significant mechanical basis to long-term stability of rock engineering [7], and the effect of creep on the stability of geotechnical engineering should be fully considered. This requires the establishment of a model that can predict the creep process of rock under different stress states and determine the creep converge time of rock.

A number of studies have been reported on creep characteristics of rock by analyzing creep strain or deformation. Wang R. et al. ${ }^{[6]}$ and Goodman R. ${ }^{[8]}$ indicated that the creep strain of a rock mass under different applied stresses can be divided into three stages: primary creep (attenuated creep), secondary creep (steady creep), tertiary creep (accelerated creep), as shown in Fig. 1. However, if the strain rate of rock in the second creep stage becomes zero, then the rock will not enter the tertiary creep stage and its strain will not increase. Zhang Y et al. ${ }^{[9]}$ indicated that only when the deviatoric stress is increased to or exceeds a certain value, the rock will enter the tertiary creep stage and its strain rate increases rapidly. Lajtai et al. ${ }^{[10]}$ and Li L. et al. ${ }^{[11]}$ considered the certain value to be the long-term strength of the rock. Therefore, whether the creep strain rate of rock decreases to zero depends on whether the deviatoric stress is greater than the long-term strength or not. Zhang Q. et al. ${ }^{[12]}$, Wu D. et al. ${ }^{[13]}$ and Cui X. et al. ${ }^{[14]}$ also indicated that when the deviatoric stress is less than the long-term strength, the steady-state creep strain rate should be zero, and the rock will not enter tertiary creep. Zhao Y et al. ${ }^{[15]}$ have shown that the creep strain $\varepsilon_{v}$ of rock consists of visco-elastic strain (reversible deformation) $\varepsilon_{v e}$ and visco-plastic strain (irreversible deformation) $\varepsilon_{v p}$, and the visco-plastic strain $\varepsilon_{v p}$ is the main reason of time-dependent delayed failure in rock engineering, as shown in Fig. 2. If the strain rate in the secondary creep stage is zero, only visco-elastic strain $\varepsilon_{v e}$ exists in creep process and the rock finally reaches a stable state. Therefore, it is of great significance to study the reversible deformation in the creep process for the long-term stability of rock engineering.

Many creep constitutive models have been developed based on different assumptions. Visco-elastic strain (reversible deformation) is one of assumptions considered in traditional models. Fahimifar A et al. ${ }^{[16]}$ proposed a 
new formulation to determine the wall displacement and convergence of tunnel based on the visco-elastic body, and compared the formulation with numerical analysis. It found that the results of numerical analysis were consistent with the results of the proposed solution. Zhao Y. et al. ${ }^{[15]}$ analyzed the visco-elastic-plastic strain characteristics of rock based on the creep test results, and proposed a creep model which can describe the loading and unloading creep behavior precisely and the full stages of creep. Zhao J. et al. ${ }^{[17]}$ conducted a true triaxial compression test, and proposed a creep model which can describe the creep behavior of hard rock under different 3D stress states. The model is composed of a parallel combination of Hooke component and damper component to describe visco-elastic behavior, and a nonlinear visco-plastic body to demonstrate irreversible creep behavior.

Most creep model can describe the relationship between the strain and time of rock, and the parameters in these creep models are identified by creep tests and data fitting. Zhang Y. ${ }^{[9]}$ and Zhang H. et al. ${ }^{[18]}$ utilized Burgers model to fit the strain-time relationship of rocks, and summed up the relationship between axial stresses and parameters of Burgers model. Cong L. et al. ${ }^{[19]}$ proposed an improved Burgers model, and indicated the relationship between deviatoric stresses with initial elastic modulus and strain rate. Mansouri H. et al. ${ }^{[20]}$ found that the axial stress has a linear relationship with the initial elastic strain, the initial elastic strain rate and the creep strain.

However, the proposed creep models need different parameters for different stress state, but these parameters are not related in a unified expression. In addition, confining pressures are not explicitly considered in the constitutive equations of these creep models, so the rock strain cannot be directly expressed by the creep models under different confining pressures and axial stresses.

In fact, confining pressure is an important factor affecting rock characteristics in creep tests. In this paper, a new parameter $D P R$, the ratio of deviatoric stress to peak strength, is proposed. The instantaneous strain and viscoelastic strain of rocks in the creep test were analyzed by $D P R$, and an improved generalized Kelvin creep model is proposed which can accurately describe the relationship between rock strain and time under different confining pressures and deviatoric stresses.

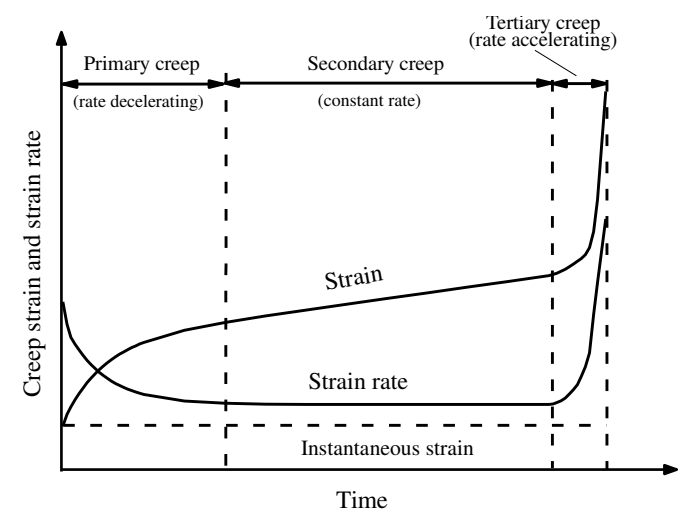

Fig. 1. A schematic presentation of rheological behavior of rock

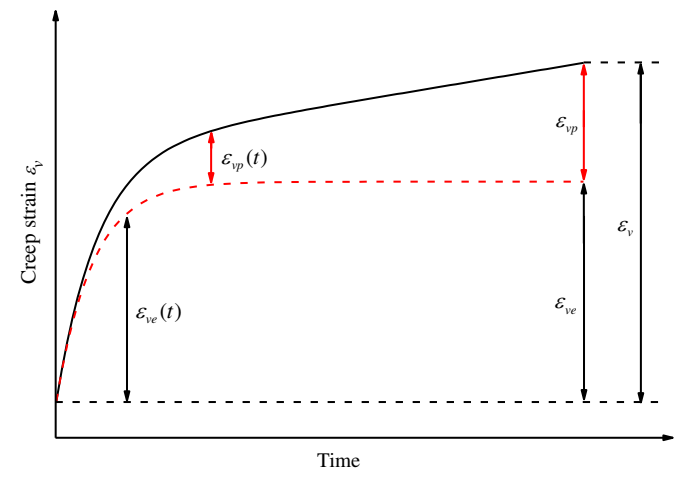

Fig. 2. Representative strain-time curve with the different types of strains

\section{MATERIAL AND METHODS}

\subsection{Rock samples and test equipment}

Rock samples for tests were granite, taken from the middle guide cave of the main and auxiliary powerhouse at the Shuangjiangkou hydropower station in western Sichuan Province, China. These sample are gray-white, mainly composed of micro-plagioclase, quartz, feldspar, and muscovite, etc. As shown in Fig. 3, those rock samples were processed into $\phi 50 \mathrm{~mm} \times 100 \mathrm{~mm}$ cylindrical standard specimens in accordance with the experimental specification 
recommended by the International Society for Rock Mechanics (ISRM).

The equipment for tests is the MTS815 rock triaxial test machine at the College of Water Resources and Hydropower, Sichuan University, as shown in Fig. 4. The major technical parameters of MTS815 are listed in Table 1. The load in the test is applied by a force sensor, and the deformation of those samples is measured by extensometers. The precision of all measured parameters is $0.5 \%$. The measurement information is collected by computers automatically to eliminate the manual error.

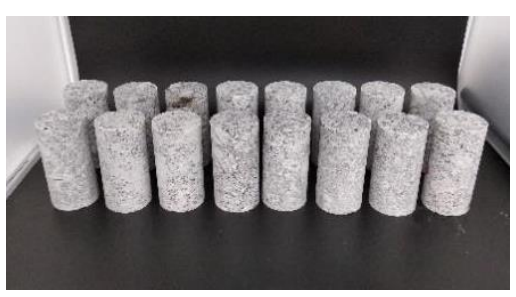

Fig. 3. Granite sample

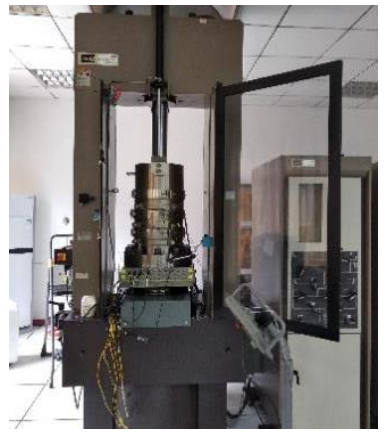

Fig. 4. Test equipment

Table 1. The major technical parameters of MTS 815

\begin{tabular}{lllll}
\hline \multirow{2}{*}{$\begin{array}{l}\text { Maximum } \\
\text { axial force }\end{array}$} & \multirow{2}{*}{$\begin{array}{l}\text { Maximum } \\
\text { confining pressure }\end{array}$} & $\begin{array}{l}\text { Operating } \\
\text { temperature }\end{array}$ & \multicolumn{2}{c}{ Extensometer resolution } \\
\cline { 4 - 5 } & & Axial & Circumferential \\
\hline $4600 \mathrm{kN}$ & $140 \mathrm{MPa}$ & $20-200^{\circ} \mathrm{C}$ & $\pm 4 \mathrm{~mm}$ & $-2.5 \sim 8 \mathrm{~mm}$ \\
\hline
\end{tabular}

\subsection{Experimental methods}

The basic parameters of the granite samples were obtained by conventional triaxial compression test, listed in Table 2. According to the result of conventional triaxial compression tests, creep tests under different confining pressures were carried out. The creep test of four samples was carried out by Chen's loading method, i.e., multistep loading method ${ }^{[21]}$. The creep test program for each granite sample was as follows: stable.

(1) Confining pressure was applied to each granite sample to a predetermined value at $0.1 \mathrm{MPa} / \mathrm{s}$, and remained

(2) The axial stress was applied to each granite sample to a predetermined value at $30 \mathrm{kN} / \mathrm{min}$. $55 \% \sim 60 \%$ of the peak strength in the conventional triaxial compression test is taken as the first stress level of the creep test under the same confining pressure, maintaining the axial stress until the strain rate was stable.

(3) The stress was increased by $10 \%$ of the peak strength as next stress level.

(4) If the strain rate at the fourth stress level remains stable, the test was finished.

Basic parameters of granite samples and each stress level scheme of triaxial creep tests are listed in Table 3.

Table 2. The basic parameters of the granite samples

\begin{tabular}{llllll}
\hline $\begin{array}{l}\text { Confining } \\
\text { pressure } \sigma_{3} \\
(\mathrm{MPa})\end{array}$ & $\begin{array}{l}\text { Peak strength } \\
\sigma_{p}(\mathrm{MPa})\end{array}$ & $\begin{array}{l}\text { Poisson's } \\
\text { ratio }\end{array}$ & $\begin{array}{l}\text { Elastic } \\
\text { modulus } \\
(\mathrm{GPa})\end{array}$ & $\begin{array}{l}\text { Friction } \\
\text { coefficient } \\
\left({ }^{\circ}\right)\end{array}$ & $\begin{array}{l}\text { Cohesion } \\
(\mathrm{MPa})\end{array}$ \\
\hline 1 & 115.73 & 0.0828 & 47.95 & & \\
3 & 142.36 & 0.1215 & 48.37 & 50.16 & 21.75 \\
5 & 157.22 & 0.1697 & 53.09 & & \\
10 & 197.97 & 0.1886 & 57.87 & & \\
\hline
\end{tabular}

Table 3. Basic parameters and triaxial creep tests scheme of granite samples

\begin{tabular}{|c|c|c|c|c|c|c|c|c|}
\hline \multirow{2}{*}{$\begin{array}{l}\text { Sample } \\
\text { number }\end{array}$} & \multirow{2}{*}{$\begin{array}{l}\text { Height } \\
(\mathrm{mm})\end{array}$} & \multirow{2}{*}{$\begin{array}{l}\text { Diameter } \\
(\mathrm{mm})\end{array}$} & \multirow{2}{*}{$\begin{array}{l}\text { Density } \\
\left(\mathrm{g} / \mathrm{cm}^{3}\right)\end{array}$} & \multirow{2}{*}{$\begin{array}{c}\text { Confining } \\
\text { pressure } \\
\sigma_{3}(\mathrm{MPa})\end{array}$} & \multicolumn{4}{|c|}{ Axial stress $\sigma_{1}(\mathrm{MPa})$} \\
\hline & & & & & $1^{\text {st }}$ level & $2^{\text {nd }}$ level & $3^{\text {rd }}$ level & $4^{\text {th }}$ level \\
\hline $\mathrm{CR}$ & 99.92 & 5 & 2. & 1 & 68.75 & 80.36 & 91.49 & 102.63 \\
\hline $\mathrm{CR}$ & & & & 3 & 79. & 92.92 & 104.48 & 117.04 \\
\hline CR-3 & 100.38 & 50.34 & 2.68 & 5 & 92.47 & 107.05 & 121.63 & 136.20 \\
\hline CR-4 & 100.33 & 50.36 & 2.66 & 10 & 119.50 & 137.58 & 155.67 & 173.75 \\
\hline
\end{tabular}

\section{ANALYSIS OF CREEP TESTS}

In this study, a new dimensionless parameter $D P R$, the ratio of deviatoric stress to the peak strength, is used to 
analyze creep tests. $D P R$ can be expressed as:

$$
D P R=\frac{\sigma_{1}-\sigma_{3}}{\sigma_{p}}
$$

where $\sigma_{1}-\sigma_{3}$ is the deviatoric stress; $\sigma_{p}$ is the peak strength.

$\sigma_{p}$ can be obtained from conventional triaxial compression tests, as shown in Table $2 ; \sigma_{p}$ is related to confining pressures and can be expressed as:

$$
\sigma_{p}=k_{1} \sigma_{3}+b_{1}
$$

where $k_{1}$ and $b_{1}$ are parameters; in this creep test, $k_{1}=8.8387$ and $b_{1}=111.34$.

It is found that the new parameter $D P R$ is a key variable to determine the creep behavior of granite instantaneous strain and creep strain under different confining pressures. Based on $D P R$, the traditional creep model is improved. Compared to previous creep model which need different parameters for different stress states, the improved model can conveniently describe the deformation of rock with time in a unified expression under given deviatoric stresses and confining pressures.

\subsection{Strain of creep tests}

According to the test program, four creep tests under different confining pressures were carried out. Fig. 5 shows the strain curves for granite samples with time under different confining pressures by using the Boltzmann superposition principle. ${ }^{[22]}$ In this study, if the creep strain rate $\left(\mathrm{h}^{-1}\right)$ is less than $3.0 \times 10^{-5}$, the creep rate is considered to be zero. In Fig. 5, the creep strain rate is almost close to zero with time in the secondary creep of all creep tests under different confining pressures. It is indicated that the final deformation of each level in all creep tests is stable and the strain is no longer increased.

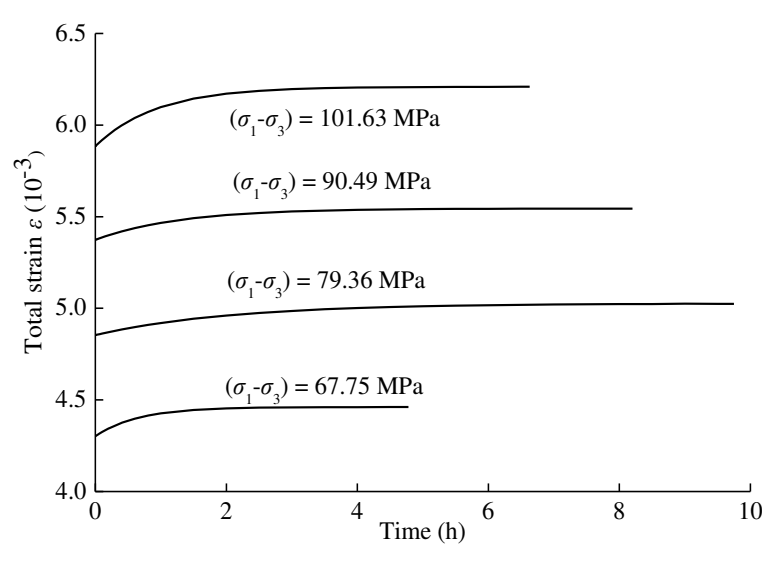

(a) $\sigma_{3}=1 \mathrm{MPa}$

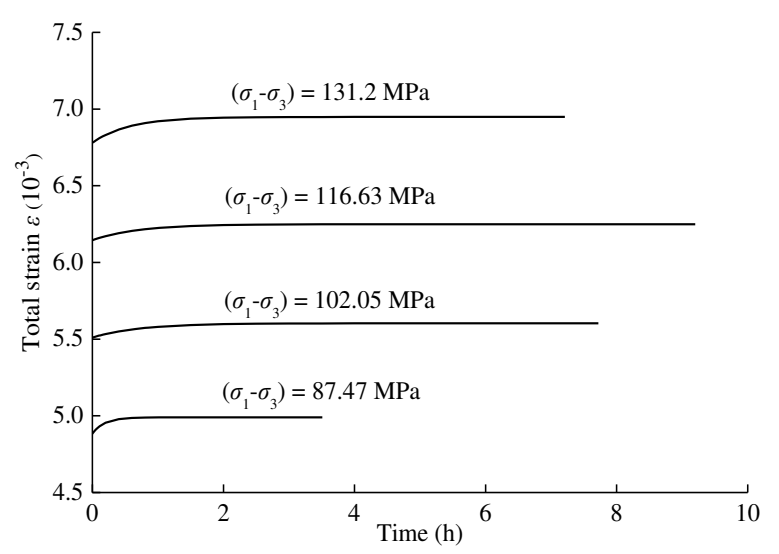

(c) $\sigma_{3}=5 \mathrm{MPa}$

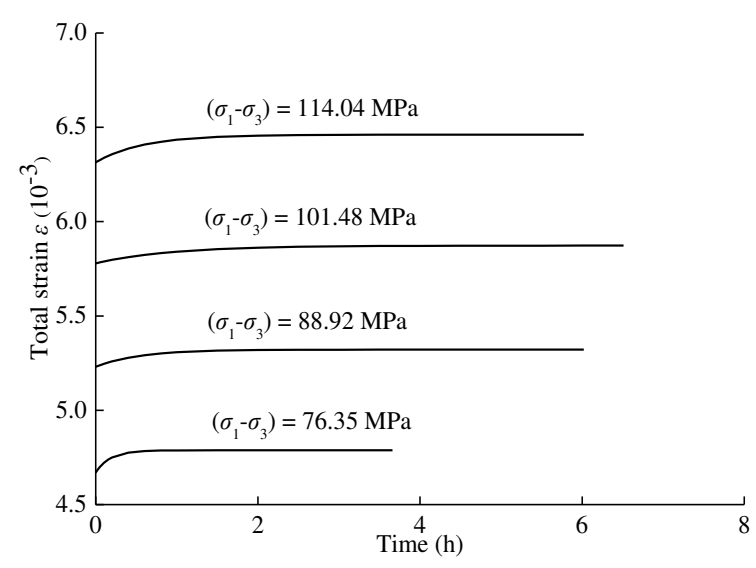

(b) $\sigma_{3}=3 \mathrm{MPa}$

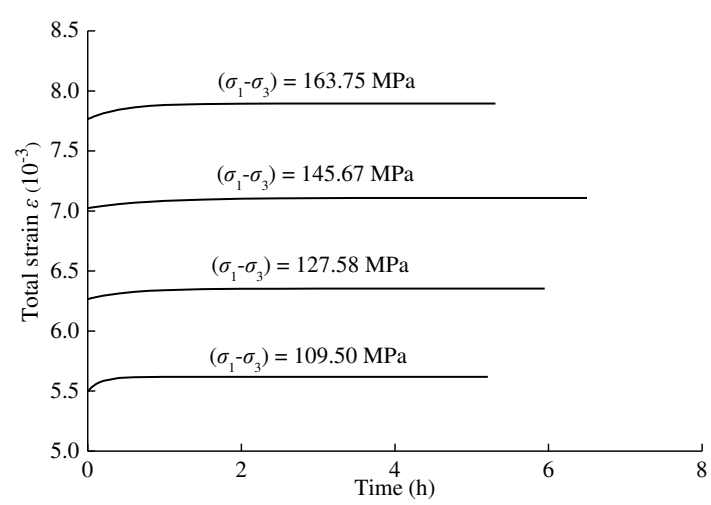

(d) $\sigma_{3}=10 \mathrm{MPa}$

Fig. 5. Curves for granite creep tests under different confining pressures and deviatoric stresses

\subsection{Instantaneous strain and Instantaneous elastic modulus}

The total strain $\varepsilon$ in creep tests can be divided into the instantaneous strain $\varepsilon_{m}$ and the creep strain $\varepsilon_{v}$, which can be 
written as ${ }^{[15]}$ :

$$
\varepsilon=\varepsilon_{m}+\varepsilon_{v}
$$

The instantaneous strain $\varepsilon_{m}$ refers to the total strain of each rock when the loading stress reaches the predetermined value in the test, that is, the total strain when $t=0$ in Fig. 5, and the creep strain $\varepsilon_{v}$ refers to the strain increment of rock with time after axial stress. The value of $\varepsilon, \varepsilon_{m}, \varepsilon_{v}$ and converge time $t$ are listed in Table 4.

Table 4. The value of $\varepsilon, \varepsilon_{m}, \varepsilon_{v}$ and converge time $t$ under different confining pressures

\begin{tabular}{|c|c|c|c|c|c|}
\hline $\begin{array}{l}\text { Confining } \\
\text { pressure (MPa) }\end{array}$ & $D P R$ & $\begin{array}{l}\text { Total strain } \varepsilon \\
\left(10^{-3}\right)\end{array}$ & $\begin{array}{l}\text { Instantaneous strain } \varepsilon_{m} \\
\left(10^{-3}\right)\end{array}$ & $\begin{array}{l}\text { Creep strain } \varepsilon_{v} \\
\left(10^{-3}\right)\end{array}$ & $\begin{array}{l}\text { Converge time } t_{c} \\
\text { (h) }\end{array}$ \\
\hline \multirow[t]{4}{*}{1} & 0.59 & 4.4609 & 4.3016 & 0.1593 & 4.78 \\
\hline & 0.69 & 5.0247 & 4.8538 & 0.1709 & 9.75 \\
\hline & 0.78 & 5.5444 & 5.3735 & 0.1709 & 8.20 \\
\hline & 0.87 & 6.2089 & 5.8847 & 0.3242 & 6.63 \\
\hline \multirow{4}{*}{3} & 0.54 & 4.7880 & 4.6697 & 0.1183 & 3.66 \\
\hline & 0.62 & 5.3213 & 5.2306 & 0.0907 & 6.02 \\
\hline & 0.71 & 5.8729 & 5.7790 & 0.0939 & 6.51 \\
\hline & 0.80 & 6.4610 & 6.3145 & 0.1465 & 6.02 \\
\hline \multirow{4}{*}{5} & 0.56 & 4.9905 & 4.8839 & 0.1066 & 3.51 \\
\hline & 0.65 & 5.6030 & 5.5103 & 0.0927 & 7.72 \\
\hline & 0.74 & 6.2495 & 6.1449 & 0.1046 & 9.20 \\
\hline & 0.83 & 6.9486 & 6.7804 & 0.1682 & 7.21 \\
\hline \multirow{4}{*}{10} & 0.55 & 5.6188 & 5.4970 & 0.1218 & 5.21 \\
\hline & 0.64 & 6.3537 & 6.2662 & 0.0875 & 5.95 \\
\hline & 0.74 & 7.1092 & 7.0236 & 0.0856 & 6.50 \\
\hline & 0.83 & 7.8949 & 7.7643 & 0.1306 & 5.31 \\
\hline
\end{tabular}

The instantaneous elastic modulus $E_{M}$ can be calculated by:

$$
E_{M}=\frac{\sigma_{1}-\sigma_{3}}{\varepsilon_{m}}
$$

Substituting Eq. (1) into Eq. (4), $E_{M}$ can be expressed as:

$$
E_{M}=\frac{\sigma_{p} \times D P R}{\varepsilon_{m}}
$$

$E_{M}$ under different confining pressures and $D P R$ are shown in Fig. 6. The instantaneous elastic modulus of rock increases with the increase of axial stresses, and shows a linear relationship which can be expressed as:

$$
E_{M}=E_{0}+\left(E_{p}-E_{0}\right) \times D P R
$$

where $E_{0}$ is the instantaneous elastic modulus at a certain confining pressure but without deviatoric stress; $E_{p}$ is the instantaneous elastic modulus at peak strength $\sigma_{p}$.

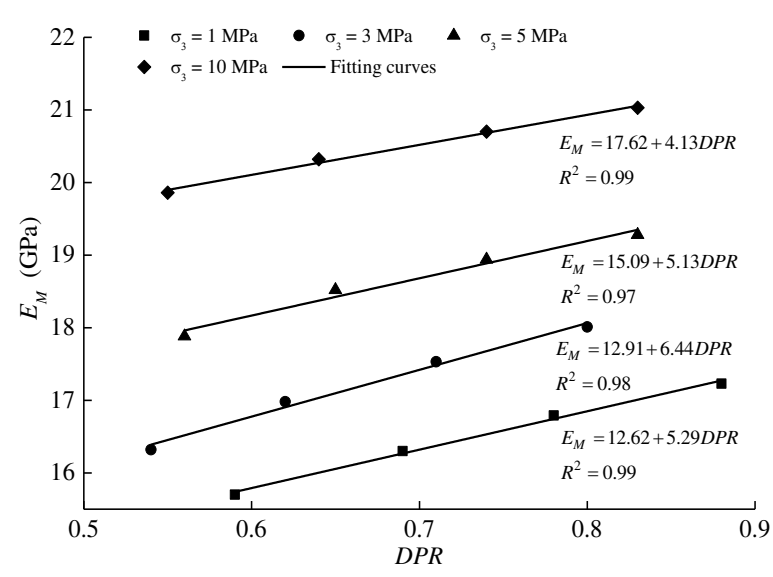

Fig. 6. Relationship between $E_{M}$ and $D P R$

Table 5. The value of $E_{p}$ and $E_{0}$ under different confining pressures

\begin{tabular}{lll}
\hline Confining pressures $\sigma_{3}$ & $E_{p}(\mathrm{GPa})$ & $E_{0}(\mathrm{GPa})$ \\
\hline 1 & 17.91 & 12.62
\end{tabular}




\begin{tabular}{lll}
3 & 19.35 & 12.91 \\
5 & 20.22 & 15.09 \\
10 & 21.75 & 17.62 \\
\hline
\end{tabular}

When $D P R=1$ and $0, E_{p}$ and $E_{0}$ can be obtained by the fitting expressions in Fig. 6, and the value of $E_{p}$ and $E_{0}$ under different confining pressures are shown in Table 5. The confining pressure has a linear relationship with $E_{p}$ and $E_{0}$. When $D P R=1,100 \%$ of the peak strength and confining pressures are applied to the rock, then $E_{p}$ can be expressed as:

$$
E_{p}=17.87+0.41 \sigma_{3}
$$

Similarly, when $D P R=0$, only the confining pressure is applied to the rock, then $E_{0}$ can be obtained by the confining pressure:

$$
E_{0}=11.76+0.59 \sigma_{3}
$$

When $\sigma_{3}=0$, the instantaneous elastic modulus of the rock under the peak strength is $17.87 \mathrm{GPa}$ at $D P R=1$; the instantaneous elastic modulus of the rock without applied stress is $11.76 \mathrm{GPa}$ at $D P R=0$.

Therefore, Substituting Eq. (6) into Eq. (5), the instantaneous strain can be expressed as follows:

$$
\varepsilon_{m}=\frac{\sigma_{1}-\sigma_{3}}{E_{M}}=\frac{\sigma_{p} \times D P R}{E_{p} \times D P R+E_{0}(1-D P R)}
$$

\subsection{Creep strain and creep elastic modulus}

Creep strain is one of the most concerned parameters in the creep test. Under the applied stress state, the creep strain increases with time, and the creep strain rate also change with time. Hence, it is significant and necessary to study the creep strain in creep test.

In this creep test, the final creep strain rate of the secondary creep of each level is 0 , indicating that the creep strain is visco-elastic strain $\varepsilon_{v e}^{[15]}$, as shown in Table 4 . The visco-elastic strain $\varepsilon_{v e}$ in creep increases with time and finally reaches maximum.

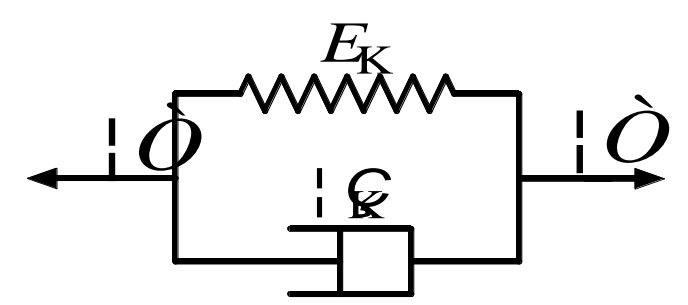

Fig. 7. Illustration of Kelvin model.

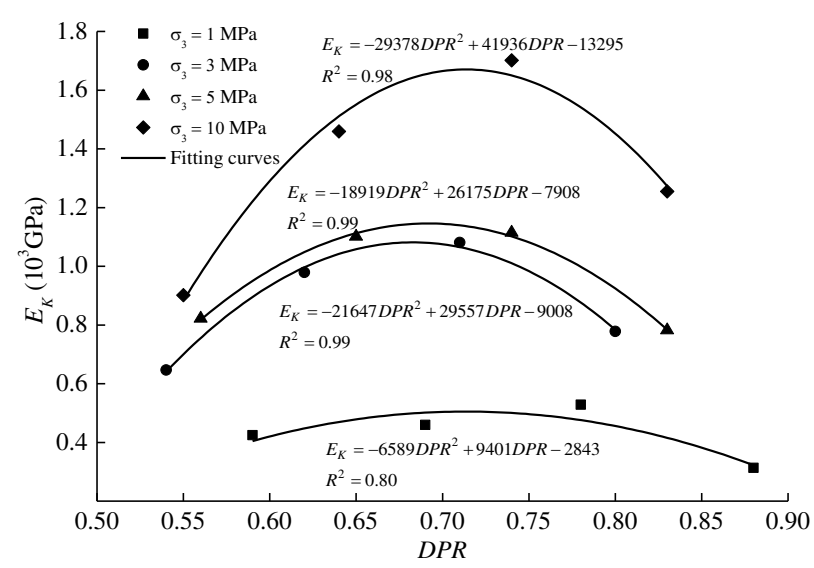

Fig. 8. Relationship between $E_{K}$ and $D P R$ under different confining pressures

The Kelvin model can well describe the visco-elastic strain in the creep with time, as shown in Fig. 7. The Kelvin model can be expressed as follows:

$$
\varepsilon_{v e}(t)=\frac{\sigma_{1}-\sigma_{3}}{E_{K}}\left(1-e^{\frac{-E_{K}}{\eta_{K}} t}\right)
$$


where $\varepsilon_{v e}(t)$ is the visco-elastic strain with time; $E_{K}$ and $\eta_{K}$ are Kelvin's creep elastic modulus and viscosity coefficient, respectively.

It can be seen from Eq. (10) that when $t=0, \varepsilon_{v e}(t)=0$, and when $t \rightarrow \infty, \varepsilon_{v e}(t)=\left(\sigma_{1}-\sigma_{3}\right) / E_{K}$. Therefore, $E_{K}$ can be defined by the final creep strain. The final creep strain can be represented by the deformation of the elastic element in Fig. 7. When $t \rightarrow \infty$, by Eq. (1) and (10), $E_{K}$ can be obtained as:

$$
E_{K}=\frac{\sigma_{1}-\sigma_{3}}{\varepsilon_{v e}}=\frac{\sigma_{p} \times D P R}{\varepsilon-\varepsilon_{m}}
$$

The relationship between $E_{K}$ and $D P R$ of rock under different confining pressures is shown in Fig. 8. The relationship between $E_{K}$ and $D P R$ is quadratic when $D P R=0.54-0.88$ in this creep test. $E_{K}$ increases first with $D P R$ and then decreases. Based on the fitting curves of the relationship between $E_{K}$ and $D P R$, it can be calculated that when $D P R=0.7134,0.6827,0.6918,0.7137$ under $\sigma_{3}=1,3,5,10 \mathrm{MPa}, E_{K}$ reaches maximum, respectively $510.75,1081.45,1146.10$ and $1670.52 \mathrm{MPa}$. The average $D P R$ when $E_{K}$ reaches maximum is 0.7004 . The maximum $E_{K}$ at a given confining pressure can be expressed as:

$$
E_{K, \max }=117.29 \sigma_{3}+545.06
$$

which $E_{K, \max }$ is the maximum $E_{K}$ at a given confining pressure.

When $D P R<0.7004$, with the increase of deviatoric stress, the internal fracture of the rock gradually close and the rock stiffness increase. When $D P R=0.7004, E_{K}$ reaches the maximum, indicating that the closing process of internal fracture of the rock is finished and the stiffness of the rock reaches the maximum. When $D P R>0.7004$, new fracture begins to form in the rock due to the increase of deviatoric stress and the rock stiffness decrease. Therefore, with the increase of $D P R$, the creep damage of rock can be divided into the fracture closure stage and fracture propagation stage. $E_{K}$ can be expressed by the closure degree of the internal fracture in the rock after the rock creep is stable, which can be expressed as:

$$
E_{K}=D_{c r}(\sigma) \times E_{K, \max }
$$

where $D_{c r}(\sigma)$ is the closure degree of the internal fracture in the rock.

Fig. 9 shows the relationship between $D_{c r}(\sigma)$ and $D P R$ under different confining pressures. Under different confining pressures, $D_{c r}(\sigma)$ corresponding to the same $D P R$ is similar. Therefore, the relationship between $D_{c r}(\sigma)$ and $D P R$ under different confining pressures can be fitted. When $D P R=0.7004, D_{c r}(\sigma)=1$, which indicates that when the deviatoric stress is $70.04 \%$ of the peak strength, the internal fracture of rock can be bestly closed.

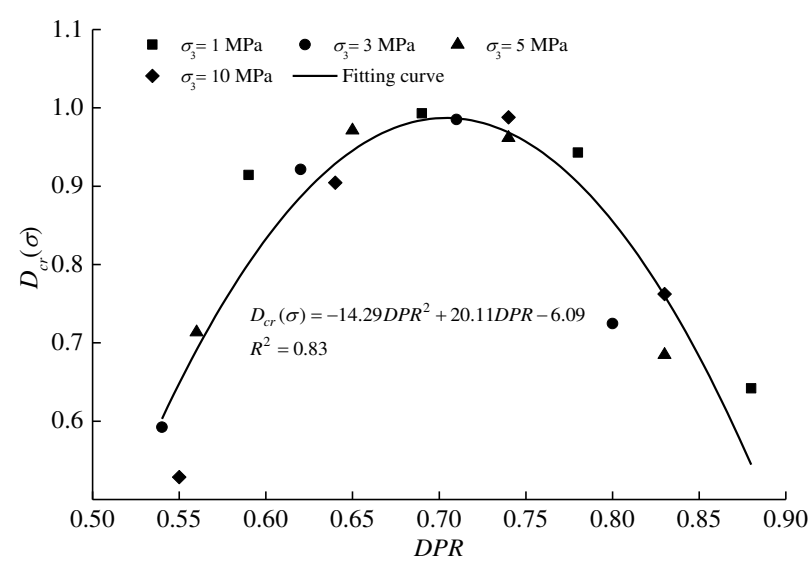

Fig. 9. Relationship between $D_{c r}(\sigma)$ and $D P R$ under different confining pressures

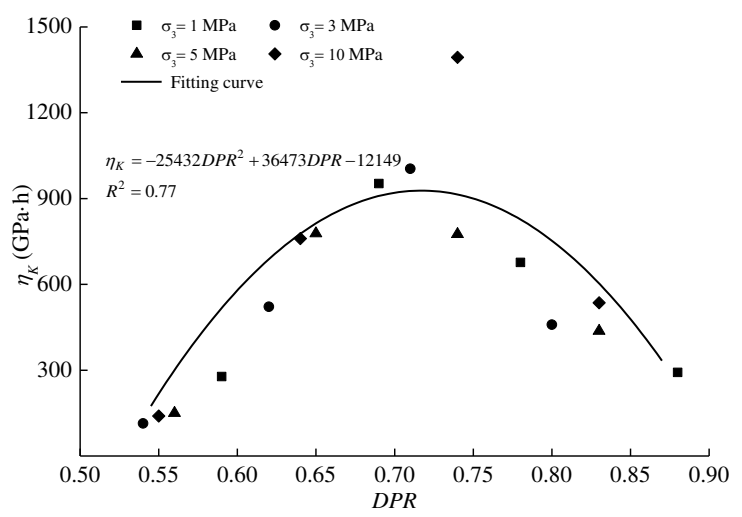

Fig. 10. Relationship between $\eta_{K}$ and $D P R$ under different confining pressures

Table 4 shows the creep strain and converge time $t_{c}$ in each level of creep test. The value of $\eta_{K}$ can be calculated 
by substituting the value of creep strain and converge time obtained from the creep test into Eq. (10) and (11), expressing as:

$$
\eta_{K}=-\frac{E_{K} \cdot t_{c}}{\ln \left(1-\frac{E_{K}}{\sigma_{1}-\sigma_{3}} \varepsilon_{v e}\right)}
$$

As shown in Fig. 10, under different confining pressures, $\eta_{K}$ at the same $D P R$ are approximately the same. The quadratic function can well describe the relationship between $\eta_{K}$ and $D P R$, expressed as:

$$
\eta_{K}=l \times D P R^{2}+m \times D P R+n
$$

where $l, m, n$ are parameters. In this study, the values of $l, m, n$ are shown in Fig. 10.

When $D P R=0.7171, \eta_{K}$ reaches the maximum, that is, $\eta_{K \text {, max }}=927.83$. Combined with $E_{K}$ analysis, it is found that $E_{K}$ and $\eta_{K}$ have the same trend of change, and reach the maximum when $D P R=0.70-0.72$, indicating that the larger $E_{K}$ is, the smaller the creep strain rate of rock is, leading to longer time for rocks to reach stable state.

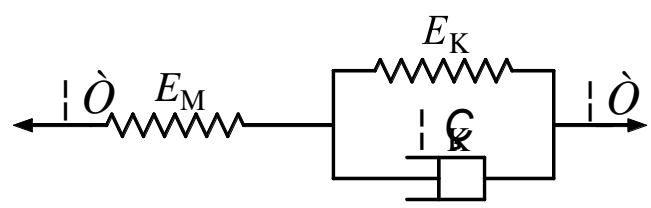

Fig. 11. Illustrations of the generalized Kelvin model

\section{IMPROVES KELVIN CREEP MODEL CONSIDERING DPR}

The time-dependent behavior of granite can be simulated by conventional creep models. The generalized Kelvin model can well describe primary creep and secondary creep with final strain rate of 0, as shown in Fig. 11. The generalized Kelvin model is composed of a Hooke body and a Kelvin model. The equation for the generalized Kelvin model can be expressed as follow:

$$
\varepsilon(t)=\frac{\sigma_{1}-\sigma_{3}}{E_{M}}+\frac{\sigma_{1}-\sigma_{3}}{E_{K}}\left(1-e^{\frac{-E_{K}}{\eta_{K}} t}\right)
$$

Based on the analysis in Section 3.2-3.3, an improved model, which can accurately describe the timedependent strain of rock, is obtained by substituting Eqs. (1), (6), (13) and (15) into Eq. (16):

$$
\varepsilon(t)=\frac{\sigma_{p} \times D P R}{E_{p} D P R+E_{0}(1-D P R)}+\frac{\sigma_{p} \times D P R}{D_{c r}(\sigma) \times E_{K, \max }}\left(1-e^{\frac{-D_{c r}(\sigma) \times E_{K, \text { max }}}{\eta_{K}} t}\right)
$$

As shown in Fig. 12, comparing the rock strain curve obtained by Eq. (17) with the creep test, it is found that the improved model for the generalized Kelvin model can effectively describe the time-dependent behavior of the granite as well as the primary and secondary creep behaviors with final strain rate of 0 under a given deviatoric stress and confining pressure. Fig. 13 shows the relationship of creep strain with time and $D P R$ under different confining pressures. When $D P R$ is about 0.7 , the creep strain will reach a minimum under different confining pressure.

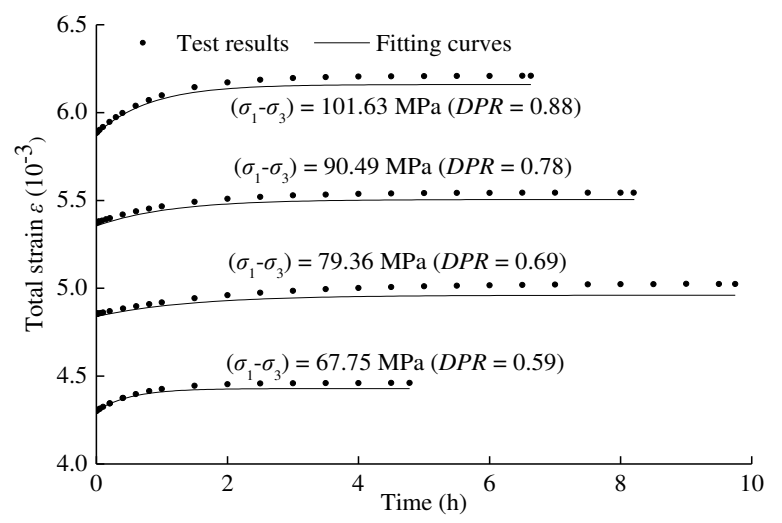

(a) $\sigma_{3}=1 \mathrm{MPa}$

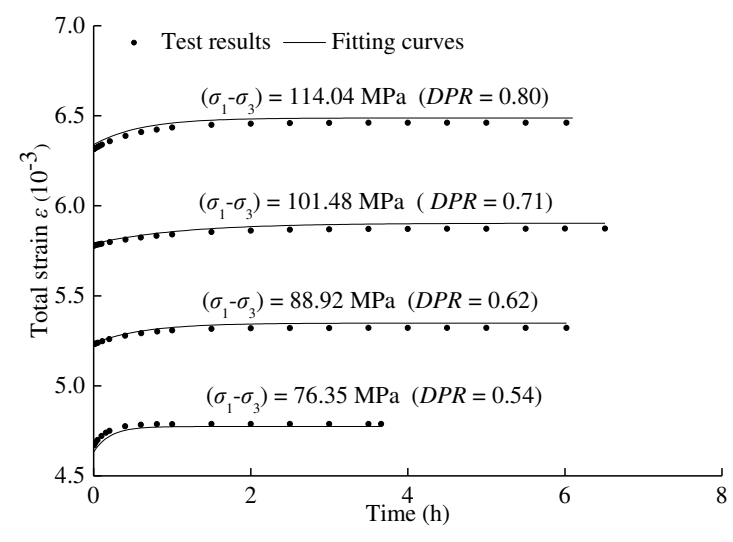

(b) $\sigma_{3}=3 \mathrm{MPa}$ 

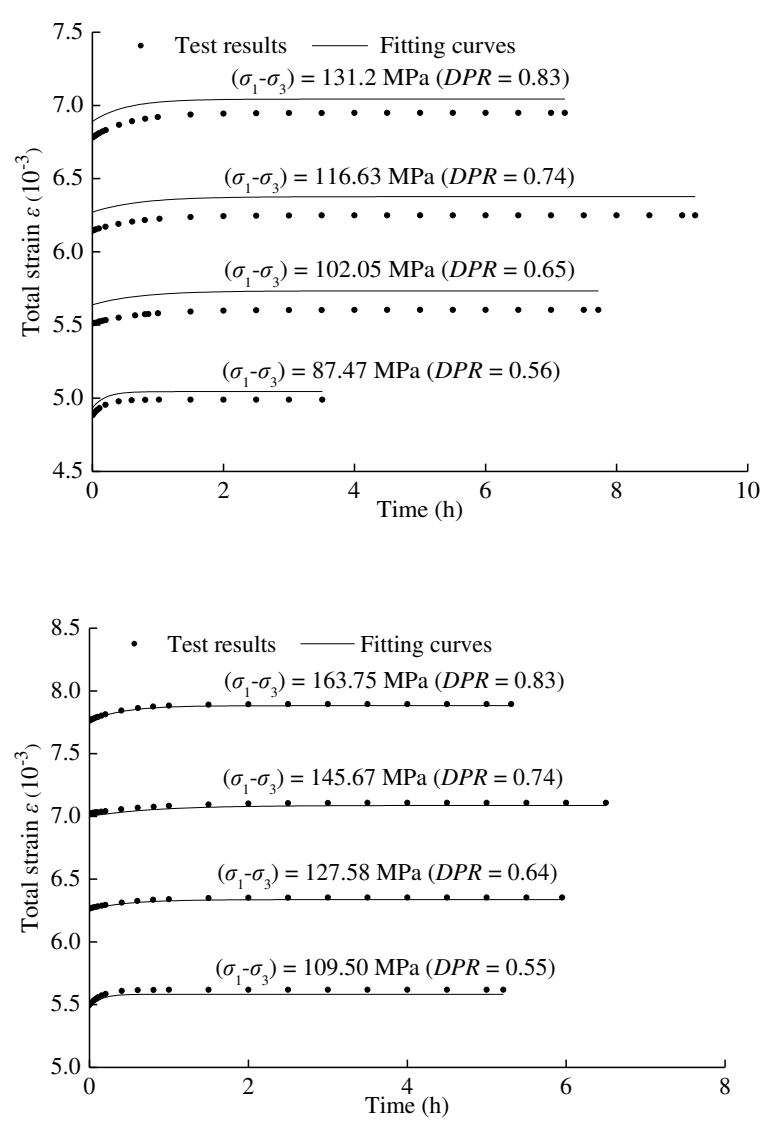

(c) $\sigma_{3}=5 \mathrm{MPa}$

(d) $\sigma_{3}=10 \mathrm{MPa}$

Fig. 12. Creep test results and calculated curves for different confining pressures and deviatoric stresses

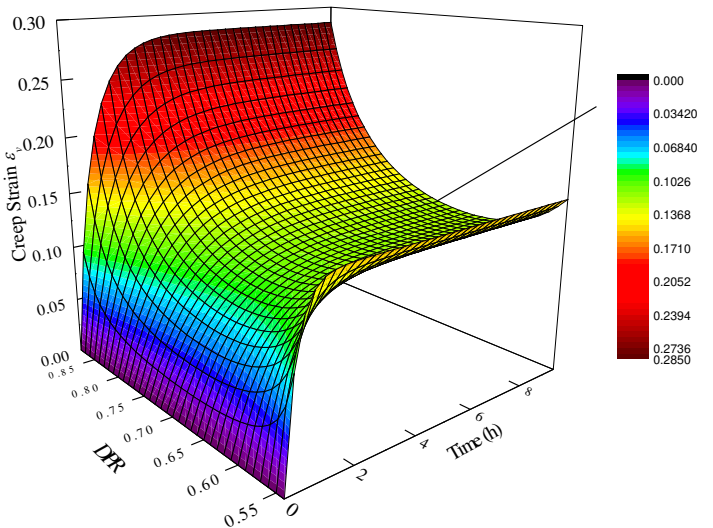

(a) $\sigma_{3}=1 \mathrm{MPa}$

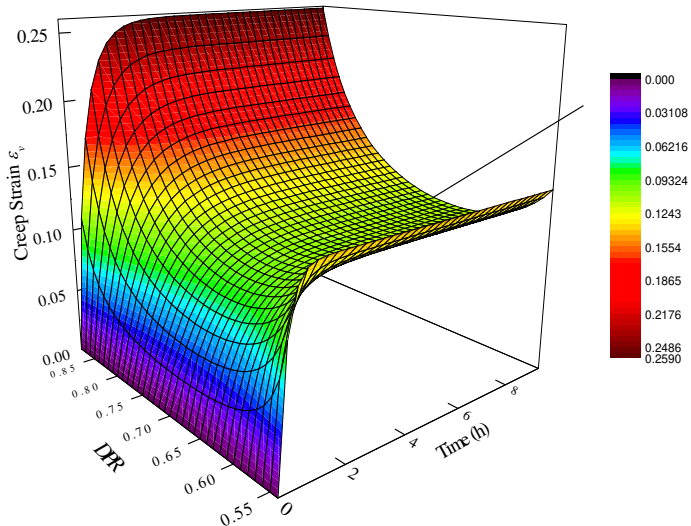

(b) $\sigma_{3}=3 \mathrm{MPa}$ 


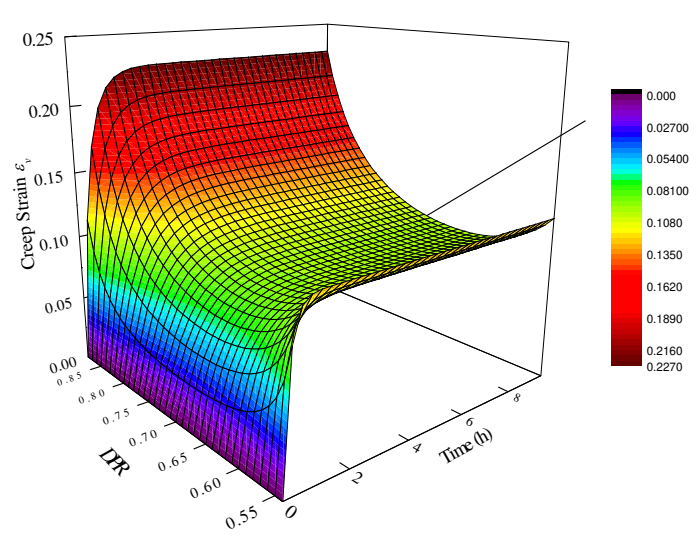

(c) $\sigma_{3}=5 \mathrm{MPa}$

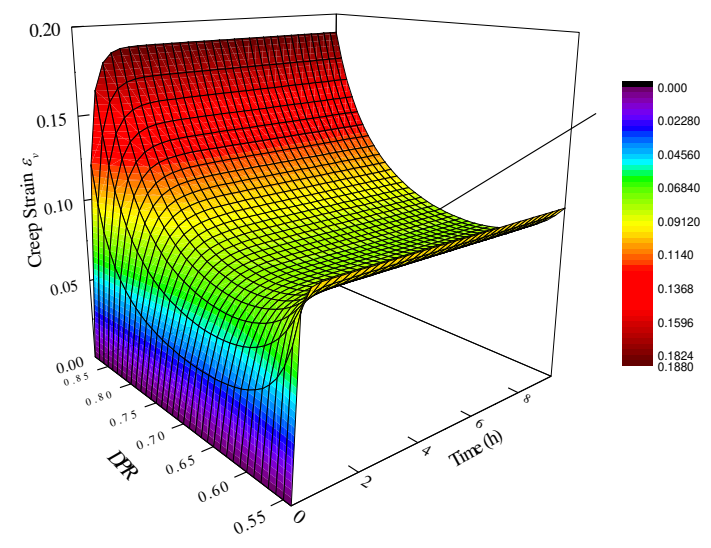

(d) $\sigma_{3}=10 \mathrm{MPa}$

Fig. 13. Relationship of creep strain with time and $D P R$ under different confining pressures

\section{DISCUSSION}

To develop a time-dependent creep model which can accurately describe the creep deformation of granite, improvements were made by introducing $D P R$ and confining pressure into the generalized Kelvin model based on the analysis of instantaneous strain and visco-elastic strain.

The tests show that instantaneous elastic modulus increases with the increase of $D P R$ under different confining pressures. Based on the analysis of the visco-elastic creep strain, it is found that the creep elastic modulus related to the final creep strain $E_{K}$ reaches the maximum when $D P R=0.7004$. The viscosity coefficient $\eta_{K}$ related to the creep converge time of rock reaches maximum when $D P R=0.7171$. Through data analysis of different rock tests in many previous studies ${ }^{[9,18,19,23,24]}$, it is found that under different confining pressures, when $E_{K}$ reaches the maximum, $D P R$ may varies from $0.45-0.76$; and when $\eta_{K}$ reaches the maximum, $D P R$ is between $0.42-0.80$. In this paper, the maximum of $E_{K}$ and $\eta_{K}$ reach maximum when $D P R=0.70-0.72$, showing the same trend of change with other researchers' work. But for the diversity of rock types, the DPR corresponding to maximum $E_{K}$ and $\eta_{K}$ may change in a rather large range.

The generalized Kelvin model considering $D P R$ can effectively predict the strain-time curve, but parameters in the model are different under different applied stresses. The relationship between creep parameters and $D P R$ is set up, so the improved generalized Kelvin model can describe the strain-time relationship under different confining pressures and deviatoric stresses.

\section{CONCLUSIONS}

Through creep tests on rock samples from the Shuangjiangkou hydropower station, the creep strain-time curves under different stresses were investigated, and the influence of the stress on the creep deformation of the rock samples was obtained. In this study, a new parameter $D P R$ is proposed, that is, the ratio of deviatoric stress to the peak strength.

The creep tests with $D P R=0.54-0.88$ is analyzed, and the following conclusions are drawn:

(1) Under different confining pressures, with the increase of $D P R$, the instantaneous elasticity modulus of rock increases linearly.

(2) The creep converge strain of rock can be reflected by Kelvin's elastic modulus $E_{K}$ which increases firstly and then decreases with the increase of $D P R$. When $D P R=0.7004, E_{K}$ reaches the maximum. With the increase of $D P R$, the creep damage of rock can be divided into the fracture closure stage and fracture propagation stage.

(3) The Kelvin viscosity coefficient $\eta_{K}$ can reflect the relationship between creep strain rate and converge time. $\eta_{K}$ increases first and then decreases with the increase of $D P R$, and the value of $\eta_{K}$ is approximately equal under different confining pressures. When $D P R=0.7171, \eta_{K}$ reaches the maximum, that is, the time for rock to reach creep stability is the longest.

(4) $D P R$ and confining pressure determine rock creep behavior and parameters. By introducing $D P R$ and confining pressure into creep model, an improved generalized Kelvin creep model is proposed which can effectively describe the primary creep behavior of granite and the secondary creep behavior under given deviatoric stresses and confining pressures.

\section{ACKNOWLEDGEMENTS}

The authors acknowledge the financial support from the National Natural Science Foundation of China (grant number U1965203), and 'The research on support time and deformation warning of surrounding rock of large 
underground cavern group under extremely high stress condition of Shuangjiangkou Hydropower' (grant number A147 SG). The authors thank Professor Jianfeng Liu for guidance with the tests.

\section{Declarations}

Conflicts of interests: the authors have no conflicts of interest to declare that are relevant to

the content of this article

Availability of data and material: Not applicable

Code availability: Not applicable

\section{REFERENCES}

[1] Brantut, N., Heap, M.J., Meredith, P.G., Baud, P. Time-dependent cracking and brittle creep in crustal rocks: a review. J. Struct. Geol. 52, 17-43, 2013.

[2] J.F. Shao, Q.Z. Zhu, K. Su. Modeling of creep in rock materials in terms of material degradation. Comput Geotech. 30(7):549-555, 2003.

[3] De-shun YIN, Yan-qing LI, Hao WU, Xiao-meng DUAN. Fractional description of mechanical property evolution of soft soils during creep. Water Sci. Eng. 6(4), 446-455, 2013.

[4] Wendong Yang, Qiangyong Zhang, Shucai Li, Shuguang Wang. Time-dependent behavior of diabase and a nonlinear creep model. Rock Mech. Rock Eng. 47, 1211-1224, 2014.

[5] U. Hunsche, N. D. Cristescu. Time Effects in Rock Mechanics. New York: Wiley. 1997.

[6] Ruofan Wang, Li Li, Richard Simon. A model for describing and predicting the creep strain of rocks from the primary to the tertiary stage. Int J Rock Mech Min Sci. 123:104087, 2019.

[7] Bourgeois F., Shao J.F, Ozanam O. An elastoplastic model for unsaturated rocks and concrete. Mech Res Commun. 29(5), 383-390, 2002.

[8] Goodman R.E. Introduction to Rock Mechanics. New York: Wiley. 1989.

[9] Yu Zhang, Wei-ya Xu, Jian-fu Shao, Hai-bin Zhao, Wei Wang. Experimental investigation of creep behavior of clastic rock in Xiangjiaba Hydropower Project. Water Sci Eng. 8(1):55-62, 2015.

[10] Lajtai E. Z., Schmidtke R.H. Delayed failure in rock loaded in uniaxial compression. Rock Mech Rock Eng. 19(1):11-25, 1986.

[11] LI Liang-quan, XU Wei-ya, WANG Wei, GUO Yun-qiang, ZHAO Hai-bin. Estimation of long-term strength for Xiangjiaba sandstone based on creep tests. Engineering Mechanics. 27(11), 127-143, 2010.

[12] Zhang Qingzhao, Shen Mingrong, Ding Wenqi. Study of mechanical properties and long-term strength of Jinping green schist. Chi J Rock Mech Eng. 31(8):1642-1649, 2012.

[13] WU Dong-sheng, Meng Lu-bo, LI Tian-bin, LAI Lin. Study of triaxial rheological property and long-term strength of limestone after high temperature. Rock Soil Mech. 37(supp.1):183-191, 2016. (in Chinese)

[14] Cui Xihai, Fu Zhiliang. Experiment study on rheology properties and long-term strength of rocks. Chi J Rock Mech Eng. 25(5):1021-1024, 2006.

[15] Yanlin Zhao, Yixian Wang, Weijun Wang, Wen Wan, Jinzhou Tang. Modeling of non-linear rheological behavior of hard rock using triaxial rheological experiment. Int J Rock Mech Min. 93:66-75, 2017.

[16] Fahimifar A, Tehrani F M, Hedayat A, Vakilzadeh A. Analytical solution for the excavation of circular tunnels in a visco-elastic Burger's material under hydrostatic stress field. Tunn. Undergr. Space Technol. 25(4), 297304,2010

[17] Jun Zhao, Xia-Ting Feng, Xiwei Zhang, Chengxiang Yang, Yangyi Zhou. Time-dependent behaviour and modeling of Jinping marble under true triaxial compression. Int J Rock Mech Min Sci. 110:218-230, 2018.

[18] Huabin Zhang, Zhiyun Wang, Yali Zheng, Pinjia Duan, Shuanglong Ding. Study on tri-axial creep experiment and constitutive relation of different rock salt. Saf Sci. 50(4):801-805, 2012.

[19] Lu Cong, Xinli Hu. Triaxial rheological property of sandstone under low confining pressure. Eng Geol. $231: 45-55,2017$.

[20] Mansouri H, Ajallocian R. Mechanical behavior of salt rock under uniaxial compression and creep tests. Int J Rock Mech Min Sci. 110:19-27, 2018.

[21] Liu X. Introduction to rock rheology. Beijing, China: Geological Publishing House, 1994.

[22] R.F. Landel, L.E. Nielsen. Mechanical Properties of Polymers and Composites. Second Edition. CRC Press, 1993.

[23] Liu Wenbo, Zhang Shuguang, Li Ruomu. Accelerated creep model of rock based on energy dissipation theory. J China Coal Soc. 44(9):2741-2750, 2019.

[24] Zhang Shuguang, Liu Wenbo, Lv Hongmiao. Creep energy damage model of rock graded loading. Result Phys. 12:1119-1125, 2019. 
Figures

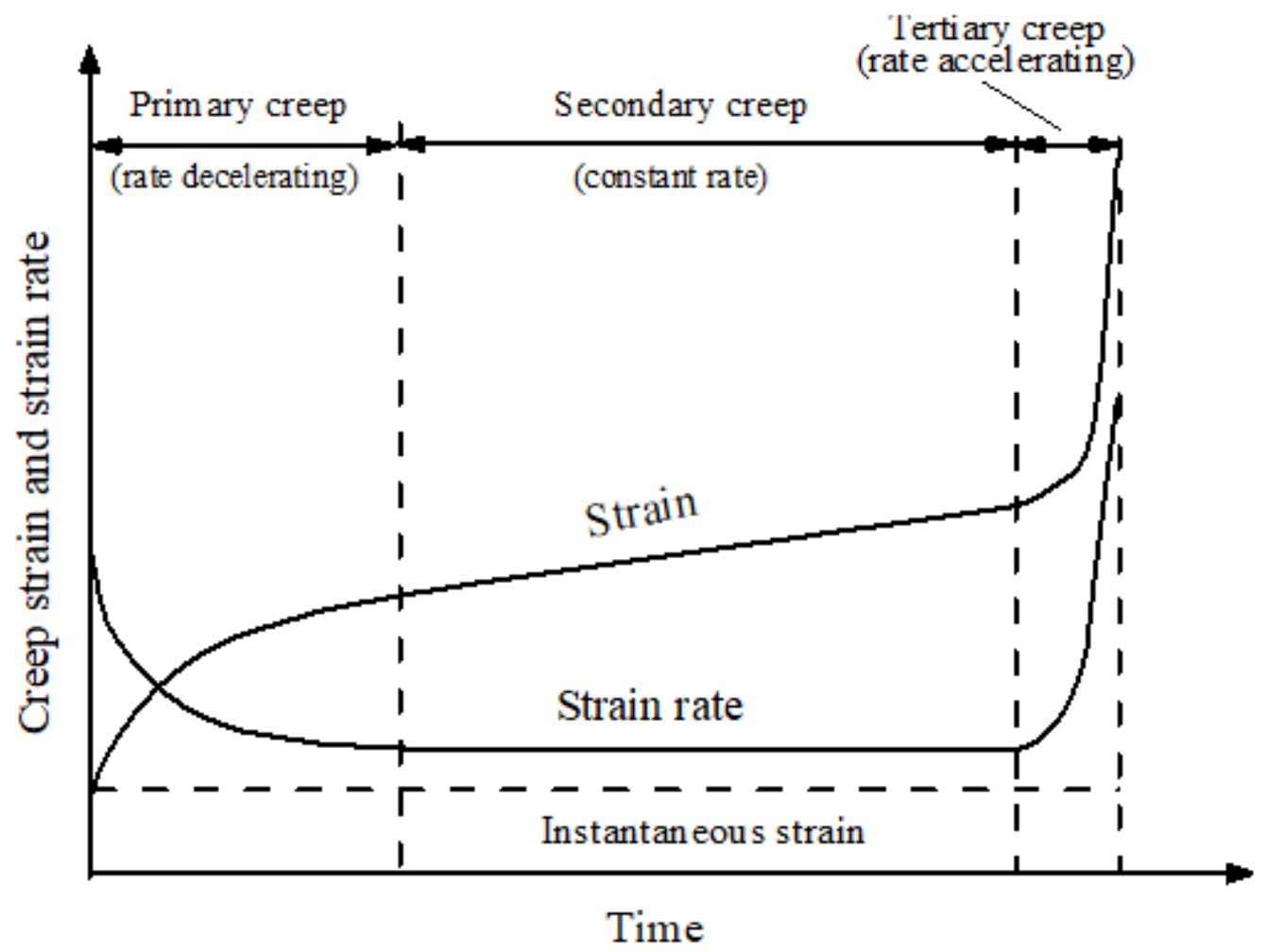

Figure 1

A schematic presentation of rheological behavior of rock 


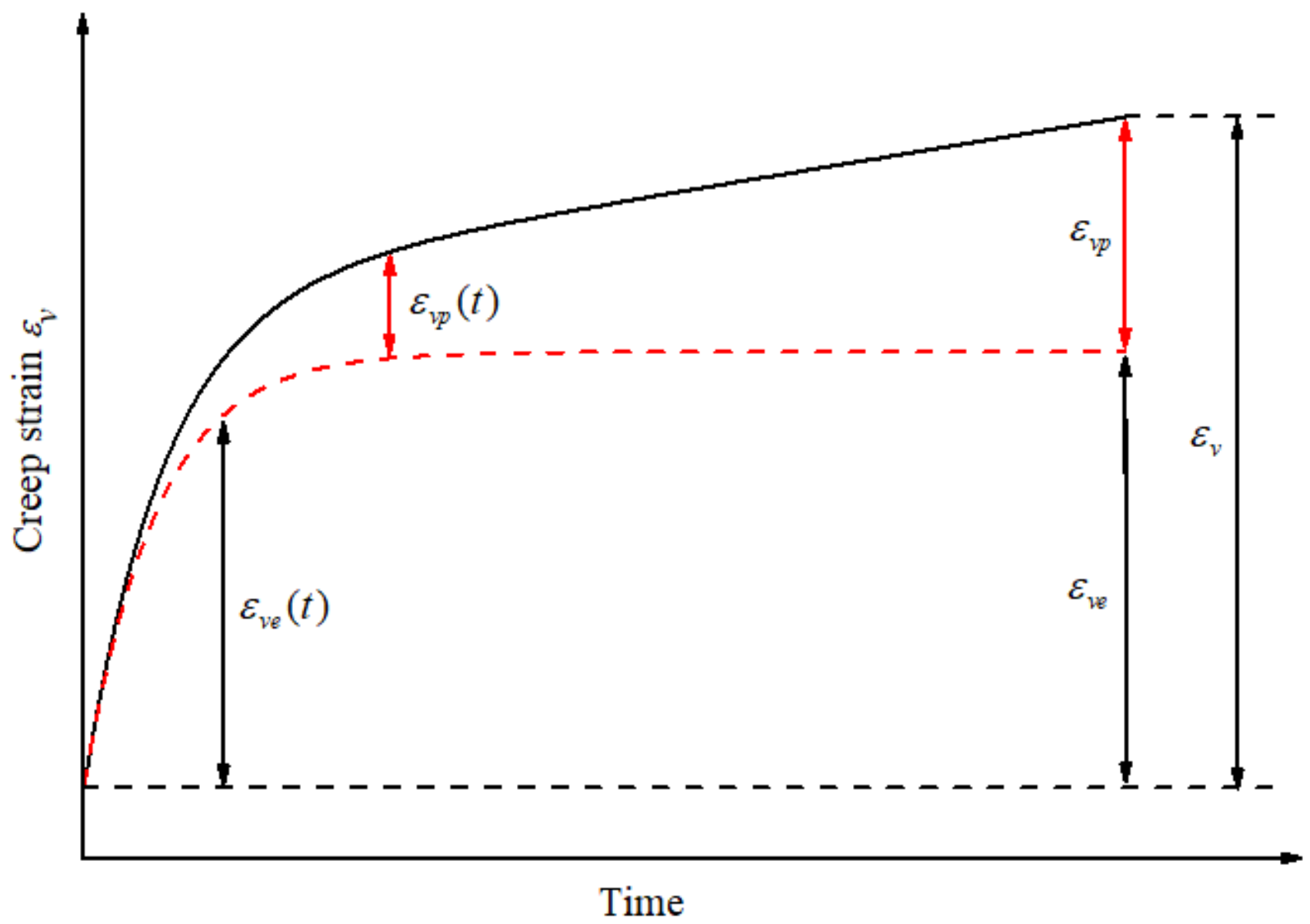

Figure 2

Representative strain-time curve with the different types of strains

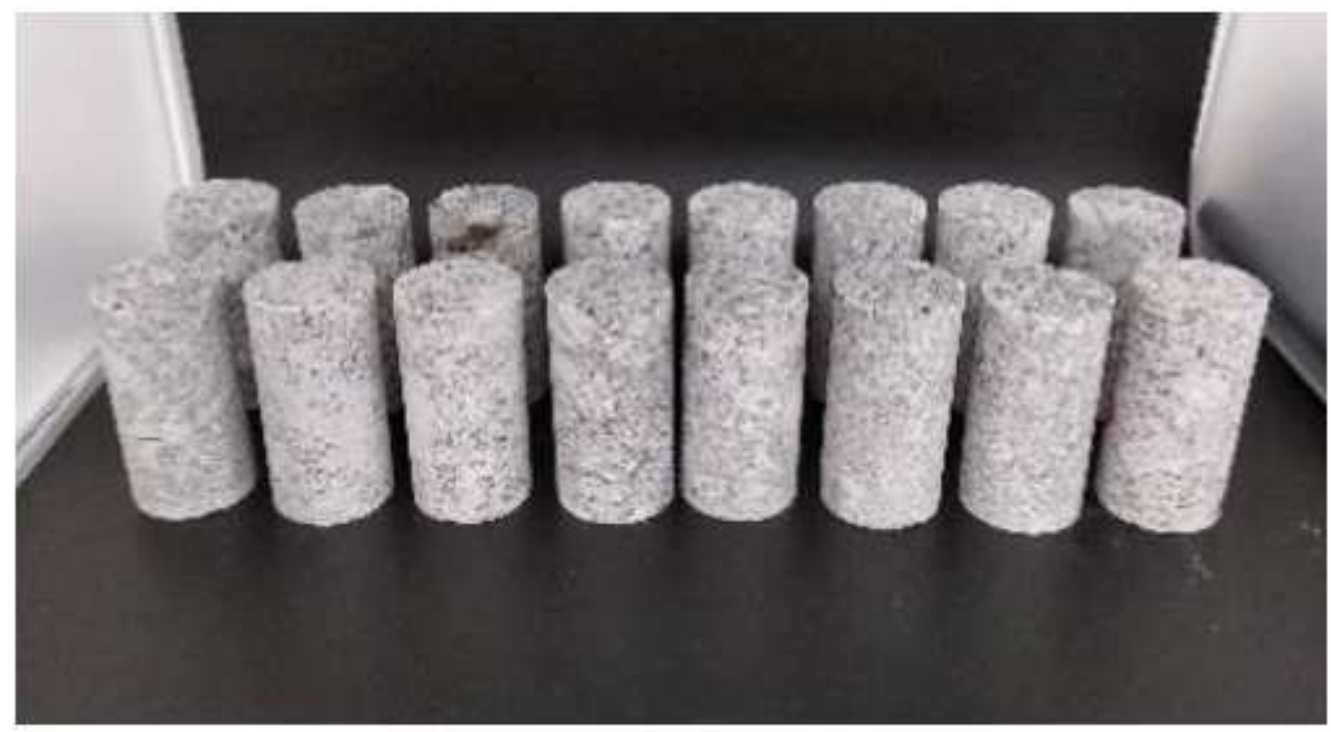

Figure 3 
Granite sample

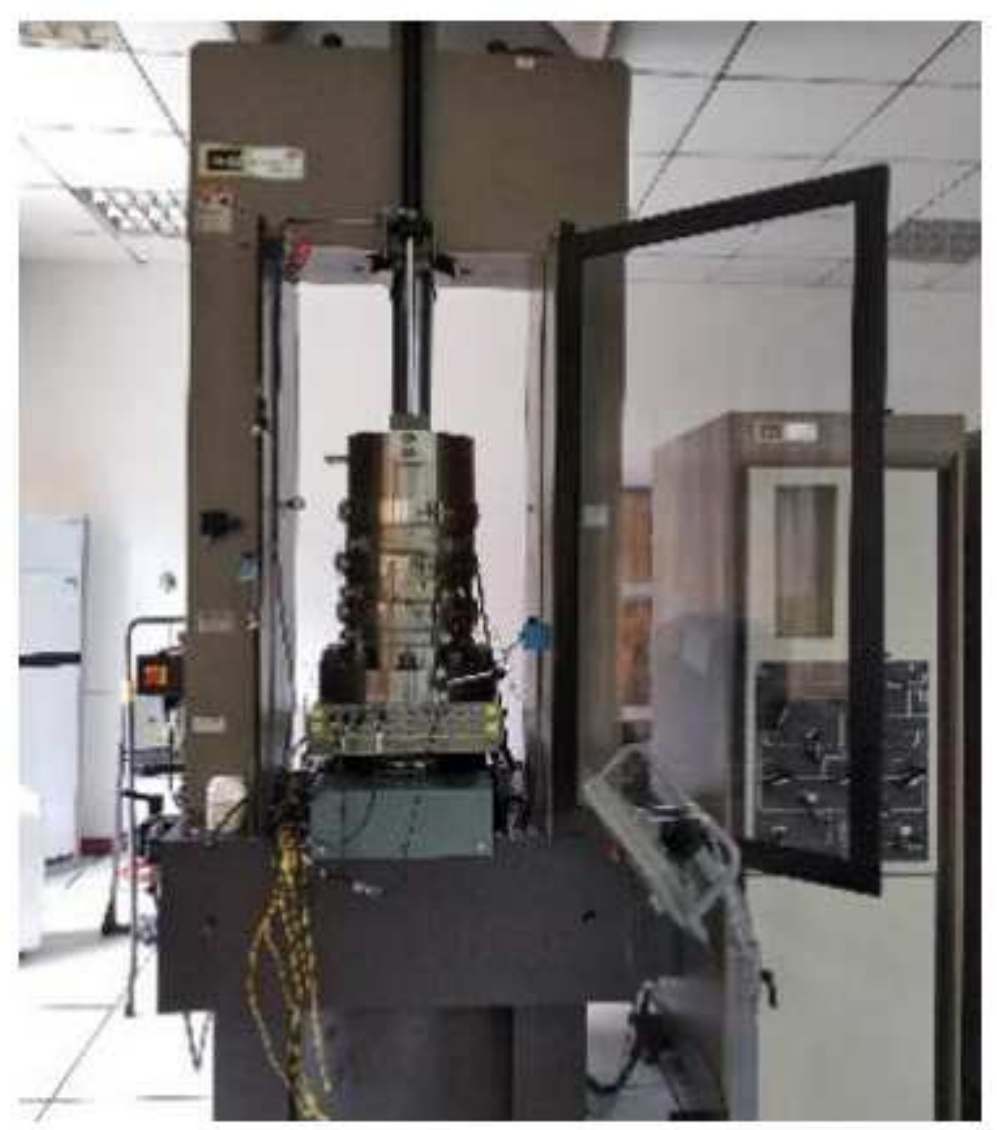

Figure 4

Test equipment 


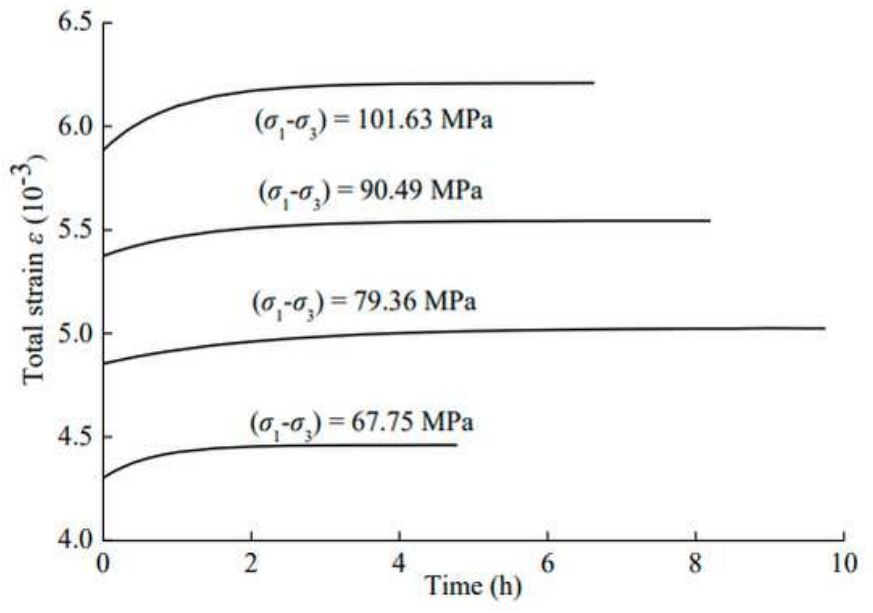

(a) $\sigma_{3}=1 \mathrm{MPa}$

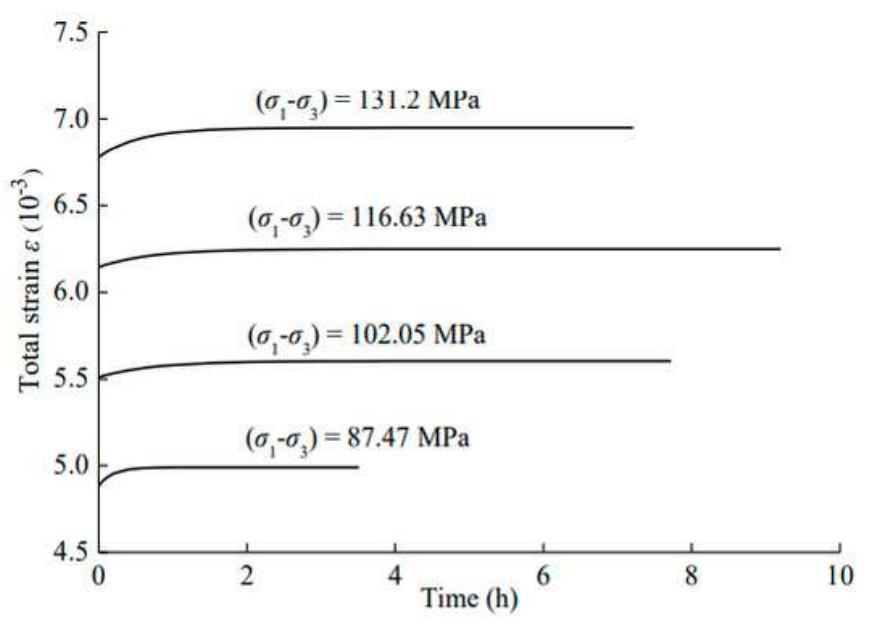

(c) $\sigma_{3}=5 \mathrm{MPa}$

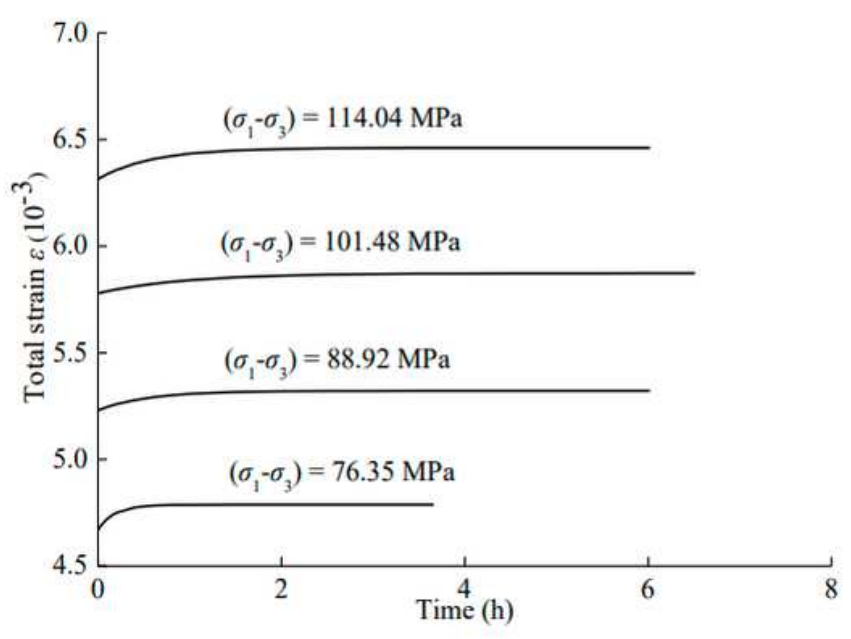

(b) $\sigma_{3}=3 \mathrm{MPa}$

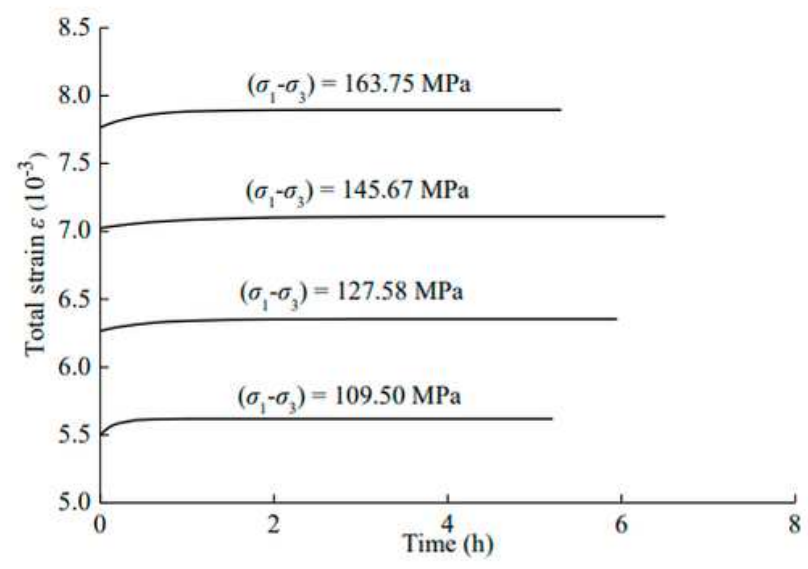

(d) $\sigma_{3}=10 \mathrm{MPa}$

\section{Figure 5}

Curves for granite creep tests under different confining pressures and deviatoric stresses 


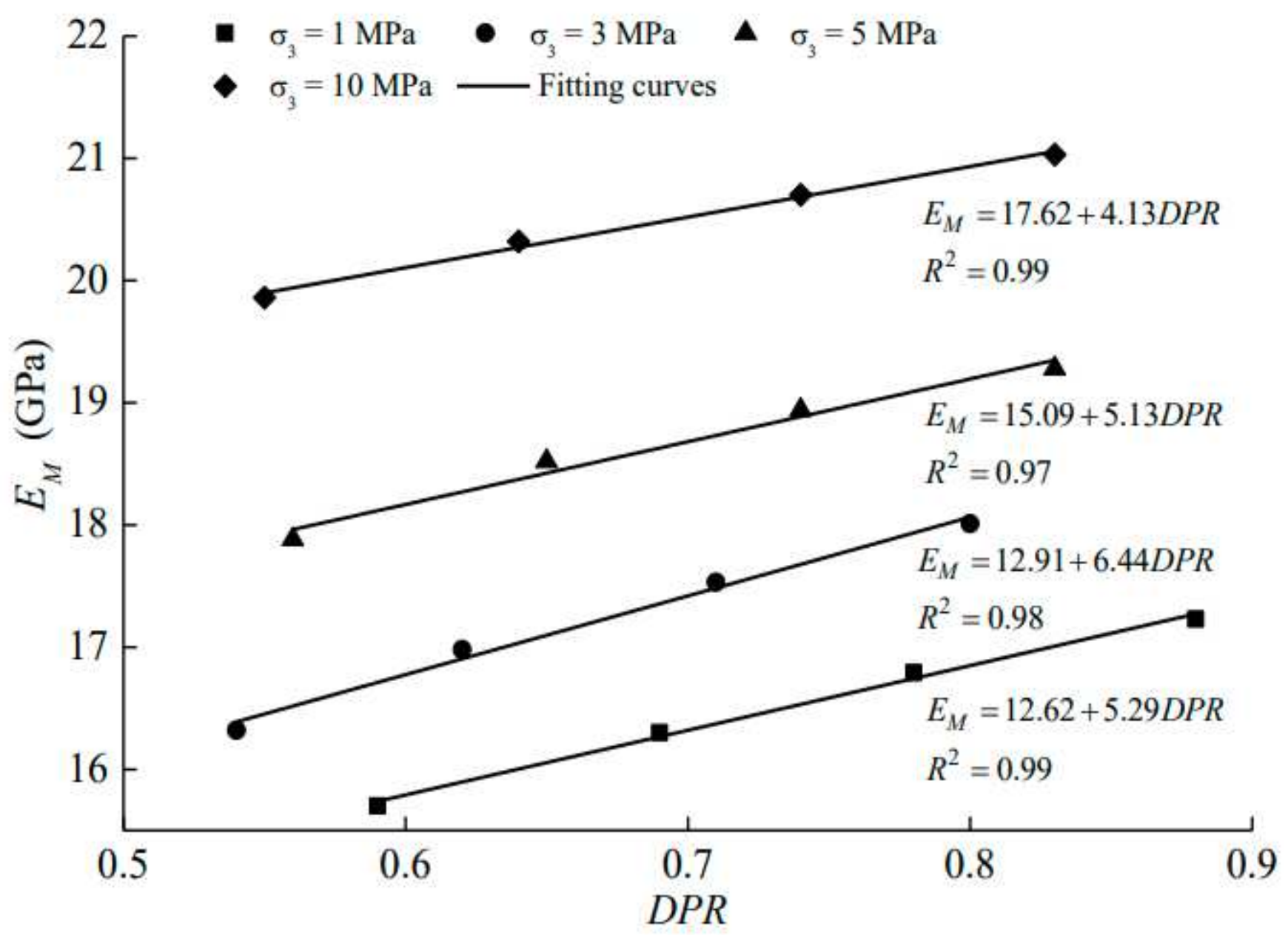

Figure 6

Relationship between EM and DPR

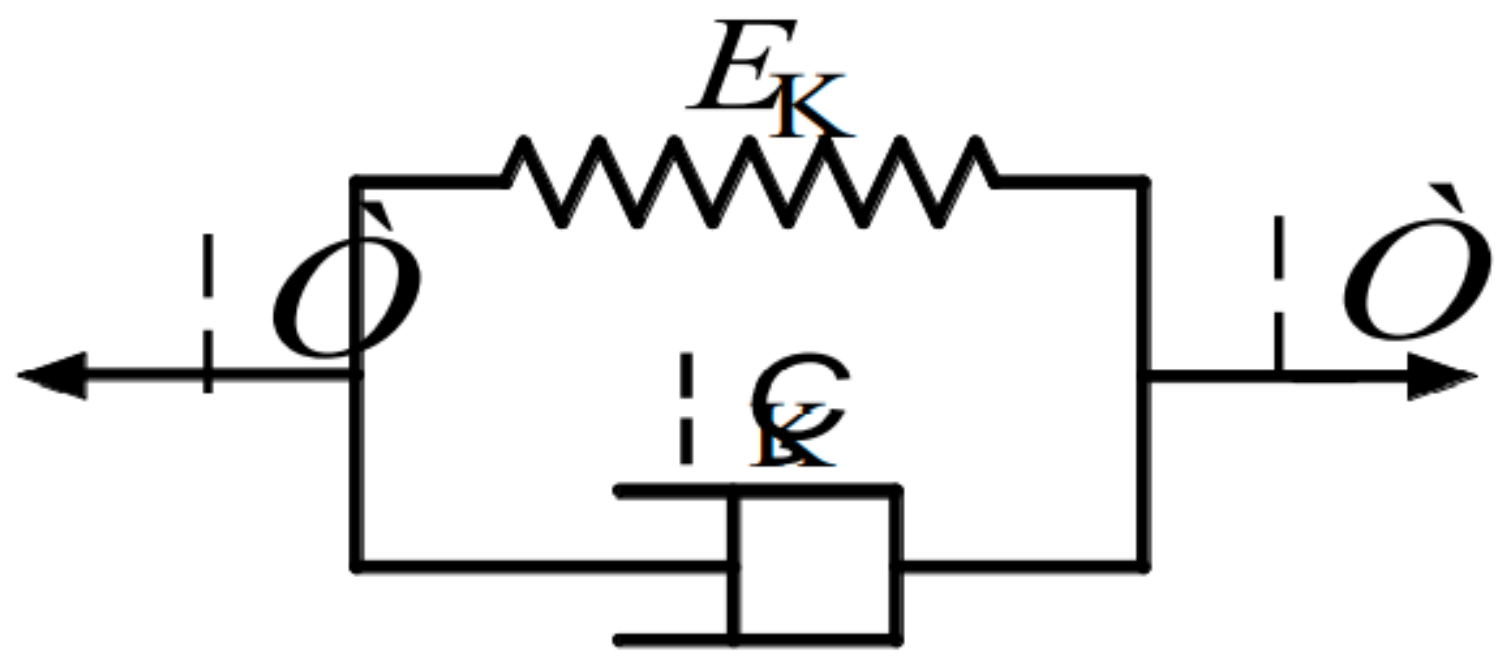

Figure 7 
Illustration of Kelvin model.

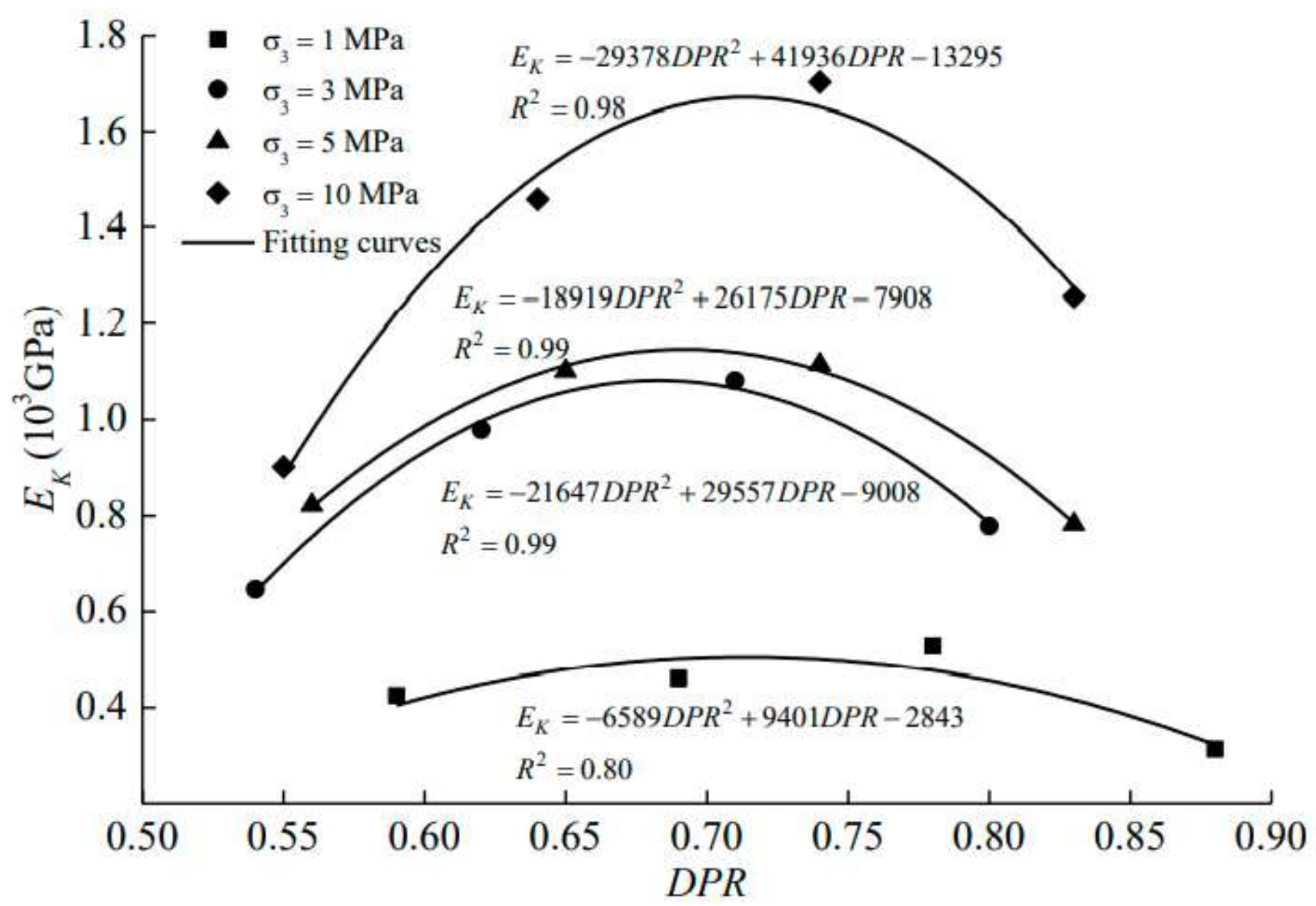

Figure 8

Relationship between EK and DPR under different confining pressures 


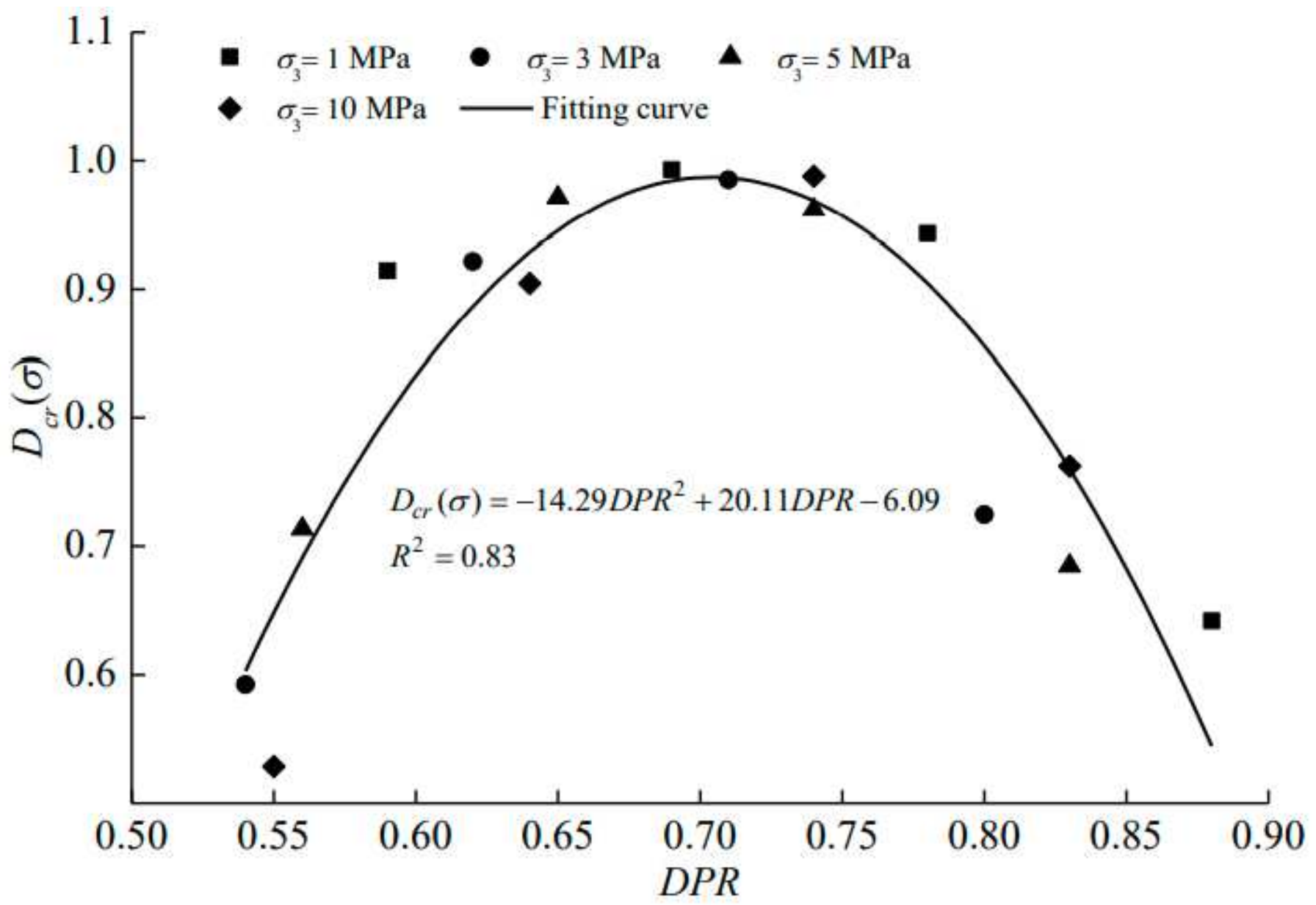

Figure 9

Relationship between $\operatorname{Dcr}(\sigma)$ and DPR under different confining pressures 


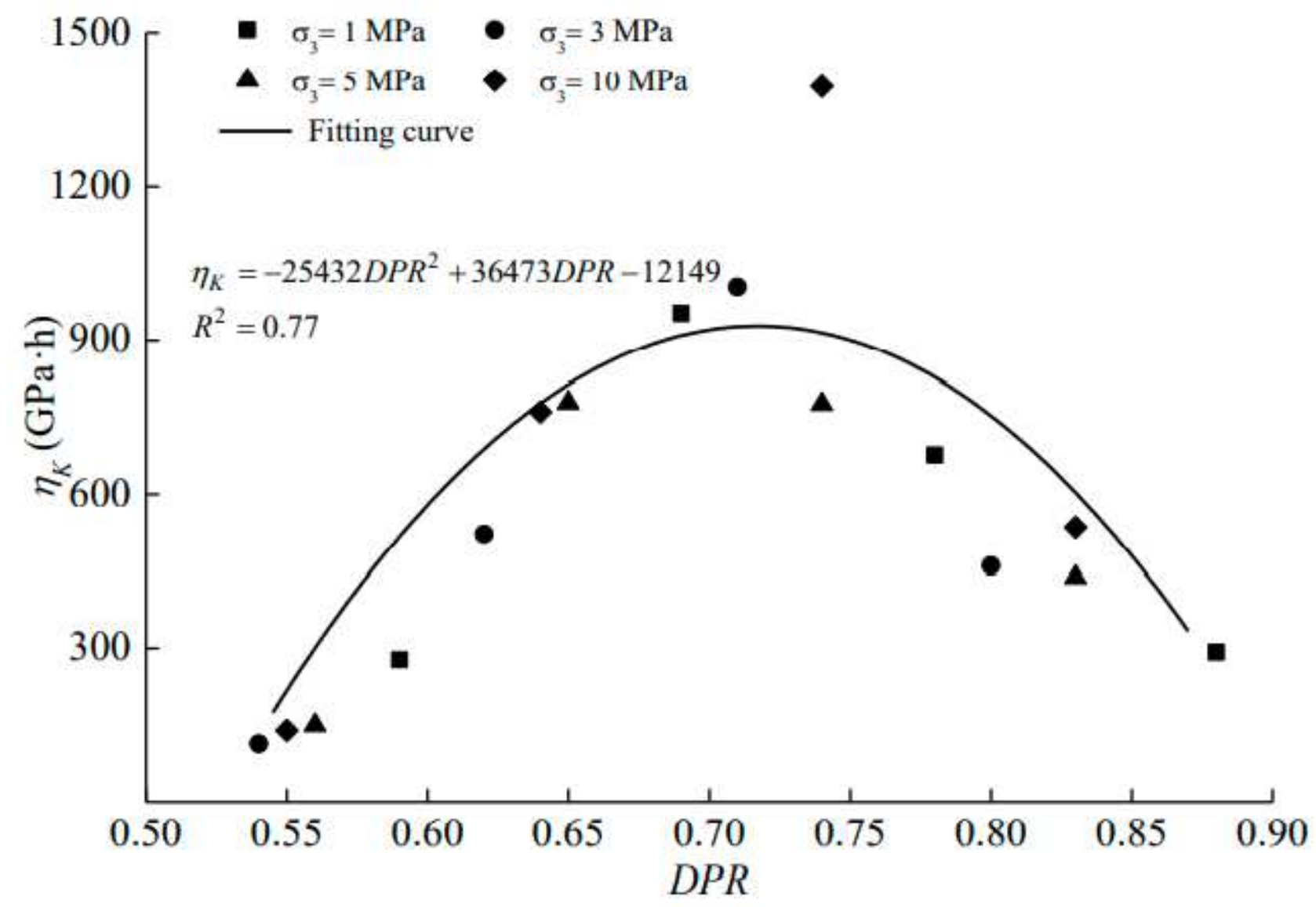

Figure 10

Relationship between $\eta \mathrm{K}$ and DPR under different confining pressures

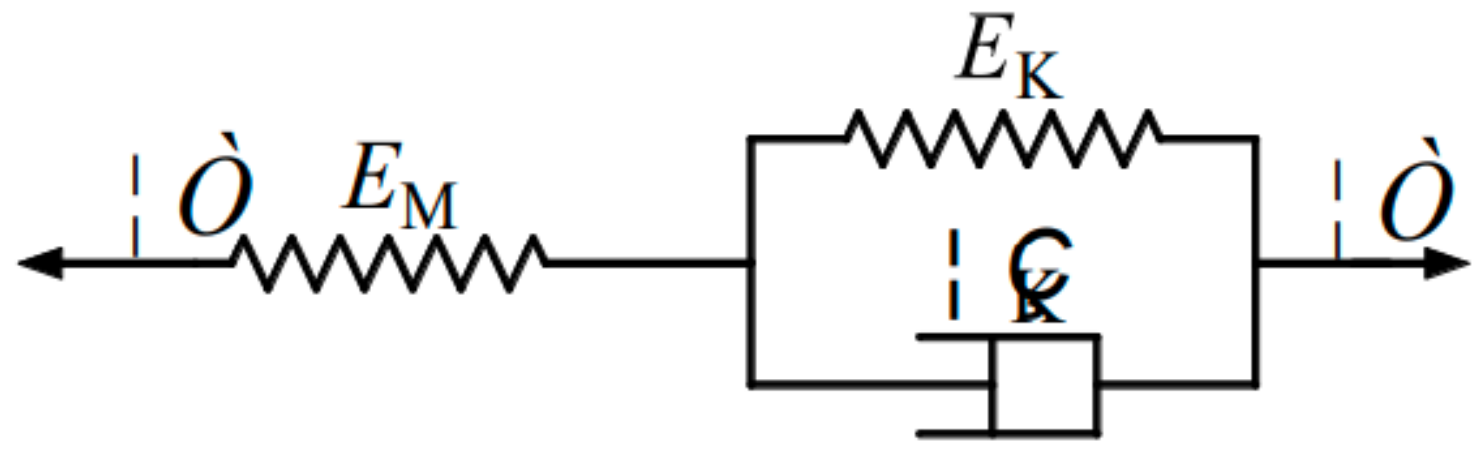

Figure 11

Illustrations of the generalized Kelvin model 


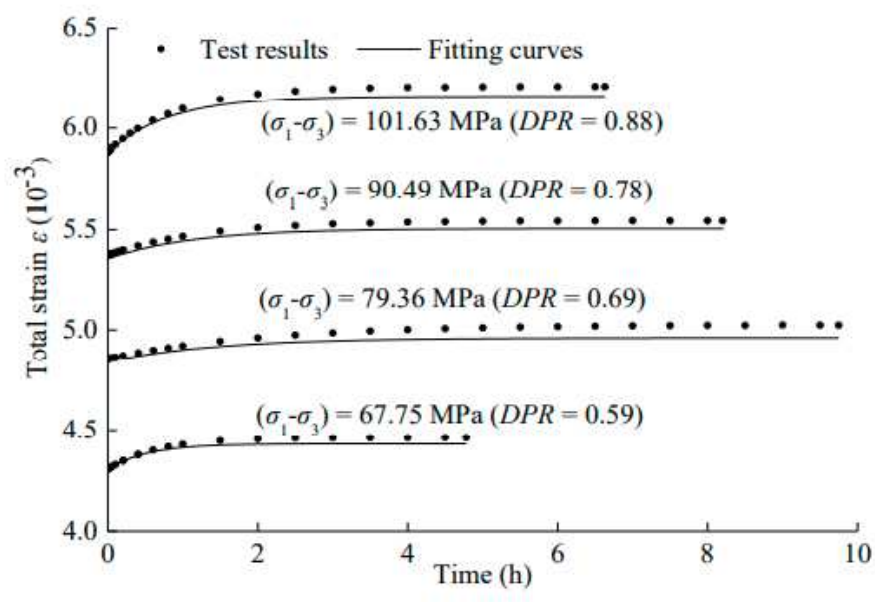

(a) $\sigma_{3}=1 \mathrm{MPa}$

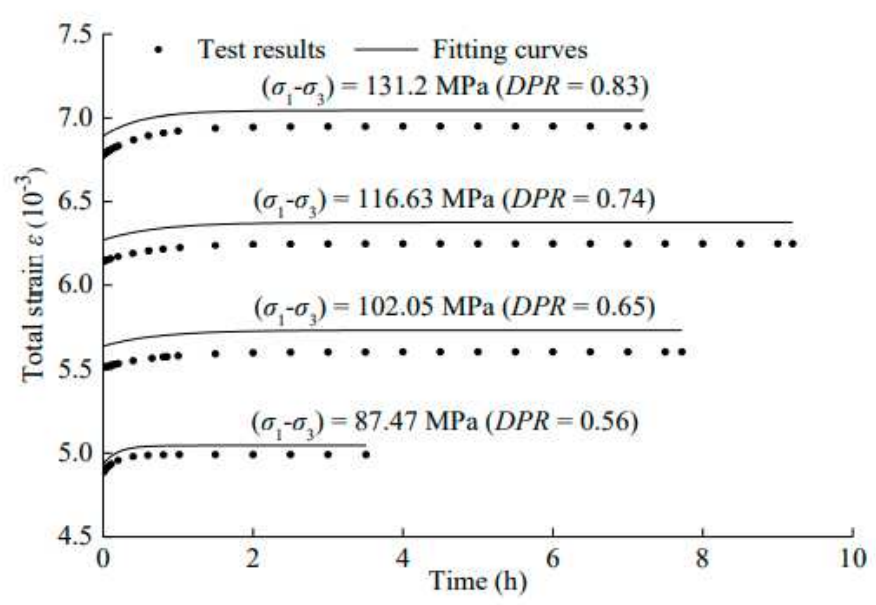

(c) $\sigma_{3}=5 \mathrm{MPa}$

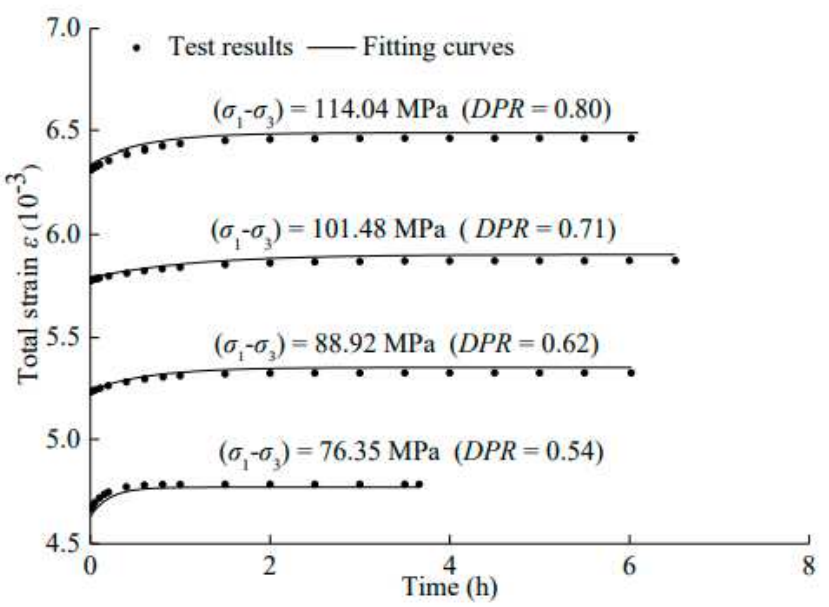

(b) $\sigma_{3}=3 \mathrm{MPa}$

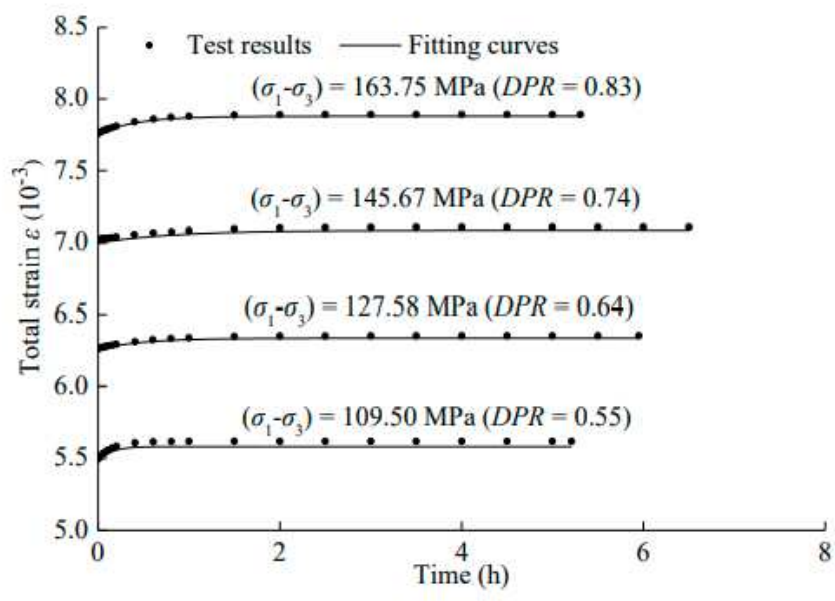

(d) $\sigma_{3}=10 \mathrm{MPa}$

\section{Figure 12}




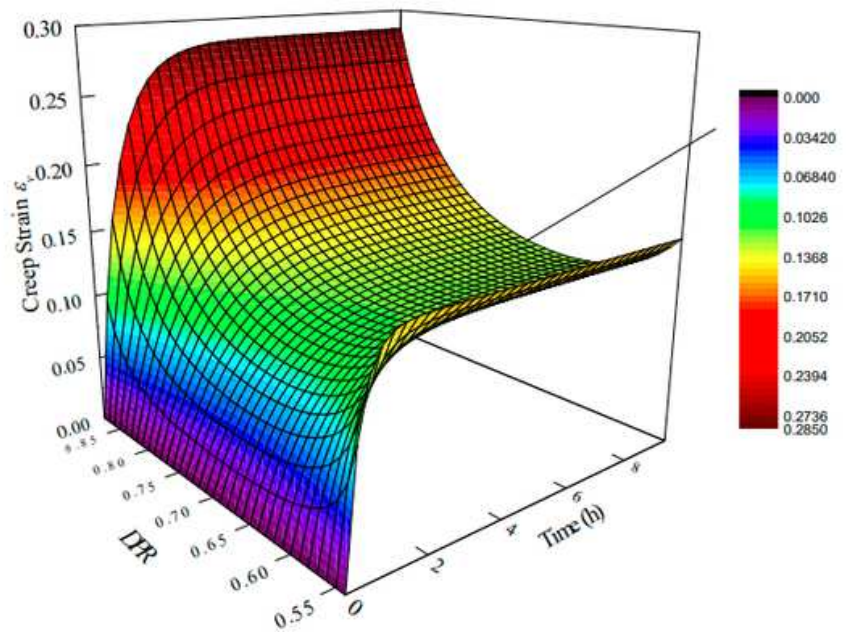

(a) $\sigma_{3}=1 \mathrm{MPa}$

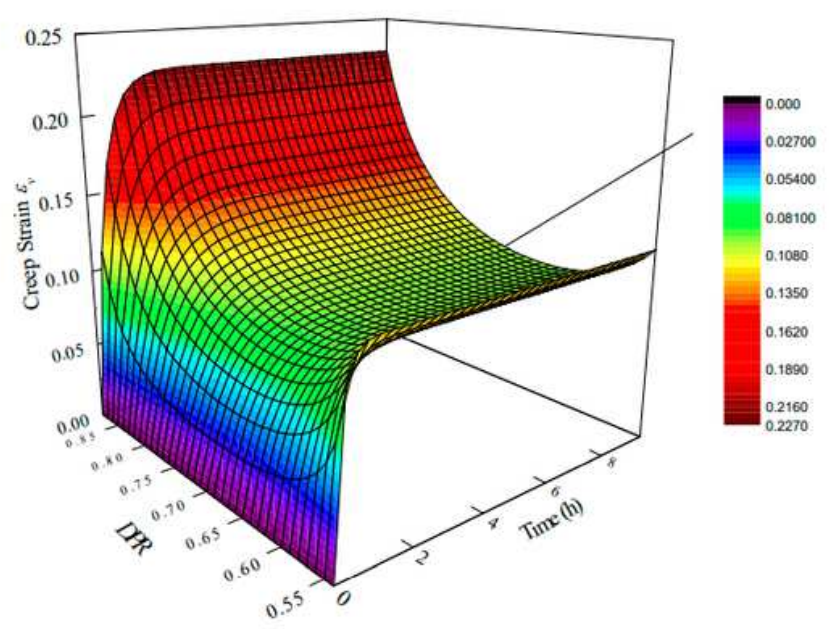

(c) $\sigma_{3}=5 \mathrm{MPa}$

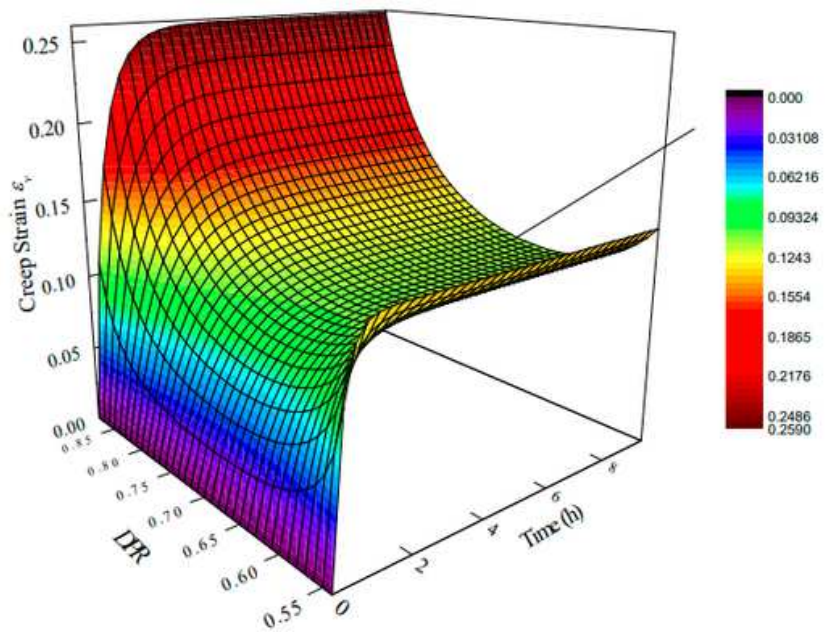

(b) $\sigma_{3}=3 \mathrm{MPa}$

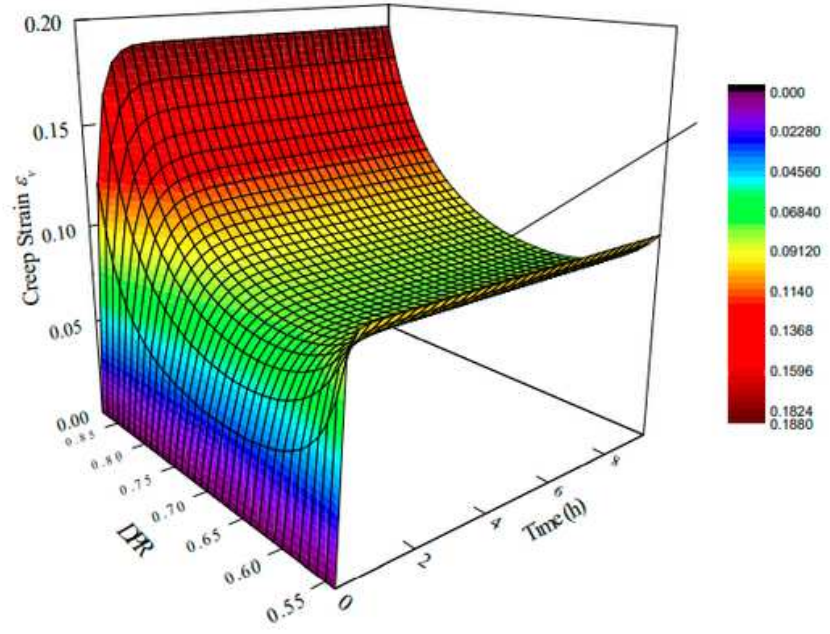

(d) $\sigma_{3}=10 \mathrm{MPa}$

Figure 13

Relationship of creep strain with time and DPR under different confining pressures 